\title{
Computational Analysis of Arc-Jet Wedge Tests Including Ablation and Shape Change
}

Tahir Gökçen, $*$ Yih-Kanq Chen, ${ }^{\dagger}$ Kristina A. Skokova, $₫$ and Frank S. Milos $§$ NASA Ames Research Center, Moffett Field, CA 94035

Coupled fluid-material response analyses of arc-jet wedge ablation tests conducted in a NASA Ames arc-jet facility are considered. These tests were conducted using blunt wedge models placed in a free jet downstream of the 6-inch diameter conical nozzle in the Ames 60-MW Interaction Heating Facility. The fluid analysis includes computational Navier-Stokes simulations of the nonequilibrium flowfield in the facility nozzle and test box as well as the flowfield over the models. The material response analysis includes simulation of two-dimensional surface ablation and internal heat conduction, thermal decomposition, and pyrolysis gas flow. For ablating test articles undergoing shape change, the material response and fluid analyses are coupled in order to calculate the time dependent surface heating and pressure distributions that result from shape change. The ablating material used in these arc-jet tests was Phenolic Impregnated Carbon Ablator. Effects of the test article shape change on fluid and material response simulations are demonstrated, and computational predictions of surface recession, shape change, and in-depth temperatures are compared with the experimental measurements.

\section{Nomenclature}

$\begin{array}{ll}C_{H} & =\text { heat transfer coefficient, } q_{w} /\left(h_{\circ}-h_{w}\right), \mathrm{kg} /\left(\mathrm{m}^{2} . \mathrm{s}\right) \\ c_{i} & =\text { mass fraction of species } i \\ h & =\text { enthalpy, MJ } / \mathrm{kg} \\ h_{\circ} & \text { total enthalpy, MJ } / \mathrm{kg} \\ h_{\circ \mathrm{cl}} & =\text { centerline total enthalpy, MJ } / \mathrm{kg} \\ \bar{h}_{\circ} & =\text { mass-averaged total enthalpy, } \int \rho u h_{\circ} d A / \int \rho u d A, \mathrm{MJ} / \mathrm{kg} \\ h_{w} & =\text { arc enthalpy, MJ } / \mathrm{kg} \\ I & =\text { Mach number } \\ M & =\text { mass flow rate, } \mathrm{g} / \mathrm{s} \\ \dot{m} & =\text { pressure, } \mathrm{kPa} \\ p & =\text { facility test box pressure, torr } \\ p_{\text {box }} & =\text { pressure gages on the calibration plate centerline }(\text { Fig. } 2 \mathrm{~b}), \mathrm{kPa} \\ p_{1}, p_{2} & =\text { total or stagnation pressure, } \mathrm{kPa} \\ p_{\circ} & =\text { model stagnation pressure or pitot pressure, } \mathrm{kPa} \\ p_{\circ 2} & =\text { model surface pressure, } \mathrm{kPa} \\ p_{s} & =\text { heat flux gages on the calibration plate centerline }(\mathrm{Fig} .2 \mathrm{~b}), \mathrm{W} / \mathrm{cm}^{2} \\ Q_{6}, Q_{7}, Q_{8} & \text { model surface heat flux, W/cm }{ }^{2} \\ q_{w} & =\text { arc length coordinate, m } \\ s & =\text { arc length coordinate of the unrecessed panel, m } \\ s^{\circ} & \end{array}$

* ELORET Corporation, MS 230-2, Senior Research Scientist, Senior Member AIAA

$\dagger$ Aerospace Engineer, Aerothermodynamics Branch, Member AIAA

‡ ELORET Corporation, Senior Research Scientist, Principal Investigator for CEV Arc-Jet Tests

$\S$ Aerospace Engineer, Thermal Protection Materials and Systems Branch, Senior Member AIAA 


$\begin{array}{ll}s_{\text {rec }} & =\text { recession normal to the unrecessed panel surface, } \mathrm{cm} \\ s_{\text {recmax }} & =\text { maximum recession on the plate centerline, cm } \\ T & =\text { temperature or translational-rotational temperature, } \mathrm{K} \\ T_{s} & =\text { model surface temperature, } \mathrm{K} \\ T_{s \max } & =\text { maximum surface temperature on the plate centerline, } \mathrm{K} \\ T_{v} & =\text { vibrational or vibrational-electronic temperature, } \mathrm{K} \\ t & =\text { time, } \mathrm{s} \\ V & =\text { arc voltage, Volt } \\ \epsilon & =\text { hemispherical emissivity } \\ \rho & =\text { density, } \mathrm{kg} / \mathrm{m}^{3}\end{array}$

\section{Introduction}

Arc-jet facilities provide the primary means to test the performance of various types of thermal protection system (TPS) materials and configurations used on the outer surfaces of spacecraft in an aerothermodynamic heating environment. In a high enthalpy arc-jet facility, a test gas, usually air or a mixture of nitrogen, oxygen and argon, is passed through an electric arc discharge where energy is added to the flow. The test gas is then expanded through a converging-diverging nozzle into an evacuated test chamber to produce high-enthalpy hypersonic flow. NASA Ames Research Center (ARC) has a number of arc-jet facilities within its Arc-Jet Complex that have long been used in development and testing of TPS for entry vehicles such as the Space Shuttle Orbiter and planetary probes. ${ }^{1-5}$

Development of efficient real gas computational fluid dynamics (CFD) codes and advances in computer technology in recent years have enabled CFD analysis to become an integral part of arc-jet testing. Computational simulations are used from the planning stages of the arc-jet experiments through post-test analysis. Recent examples of such CFD analysis for complex arc-jet test configurations were reported in Refs. 6-12. For these tests, material thermal response simulations were decoupled from the CFD computations. However, if the TPS material is significantly changing shape with time, the thermal response/ablation model and CFD analysis should take into account the changes in the surface heat flux and pressure distributions on the test article due to the shape change. For certain arc-jet tests, the shape change and its effect on the surface heat flux and pressure distributions are relatively small, and decoupled simulations may be adequate. Generally, though, both the heat flux and its distribution are sensitive to the shape of the test article. Therefore, when there is significant shape change during a test, fluid dynamics and solid thermochemical simulations need to be coupled. ${ }^{13,14}$

The primary objective of the paper is to report coupled CFD/material response analyses of ablation tests conducted in a NASA ARC arc-jet facility. The ablating material used in these tests was Phenolic Impregnated Carbon Ablator (PICA), which is a low density TPS material developed at NASA ARC in the 1990s. ${ }^{15,16}$ PICA was used to construct the heatshield for the Stardust sample-return capsule and the Mars Science Laboratory entry vehicle. ${ }^{11}$ It was also one of the two final candidate heatshield materials for the Orion Crew Exploration Vehicle. ${ }^{17}$ The Orion TPS Advanced Development Project conducted a large number of arc-jet tests to evaluate its performance over a wide range of aerothermal heating conditions, and a database was generated for development and validation of the PICA thermal response/ablation model. ${ }^{18,19}$ In Ref. 14, coupled simulations were used to analyze the ablation data obtained with stagnation arc-jet models. The present paper will focus on analysis of ablation tests conducted using PICA test articles mounted on blunt wedge model holders.

Because of the ablation and shape change that occur in these tests, coupled fluid-material response analyses are performed. As in the earlier work, ${ }^{14}$ arc-jet CFD analysis comprises simulations of the nonequilibrium flowfield in the facility nozzle, test box, and over the model. The material response analysis includes simulation of two-dimensional surface ablation and internal heat conduction, thermal decomposition, and pyrolysis gas flow. For these simulations, the CFD and material response codes are loosely coupled. Briefly, this means that the CFD simulations are started with the unablated shape, and its surface heating and pressure distributions are computed; after that, the material response model is run until a predetermined recession level is reached at some point on the model. Then, a new CFD 


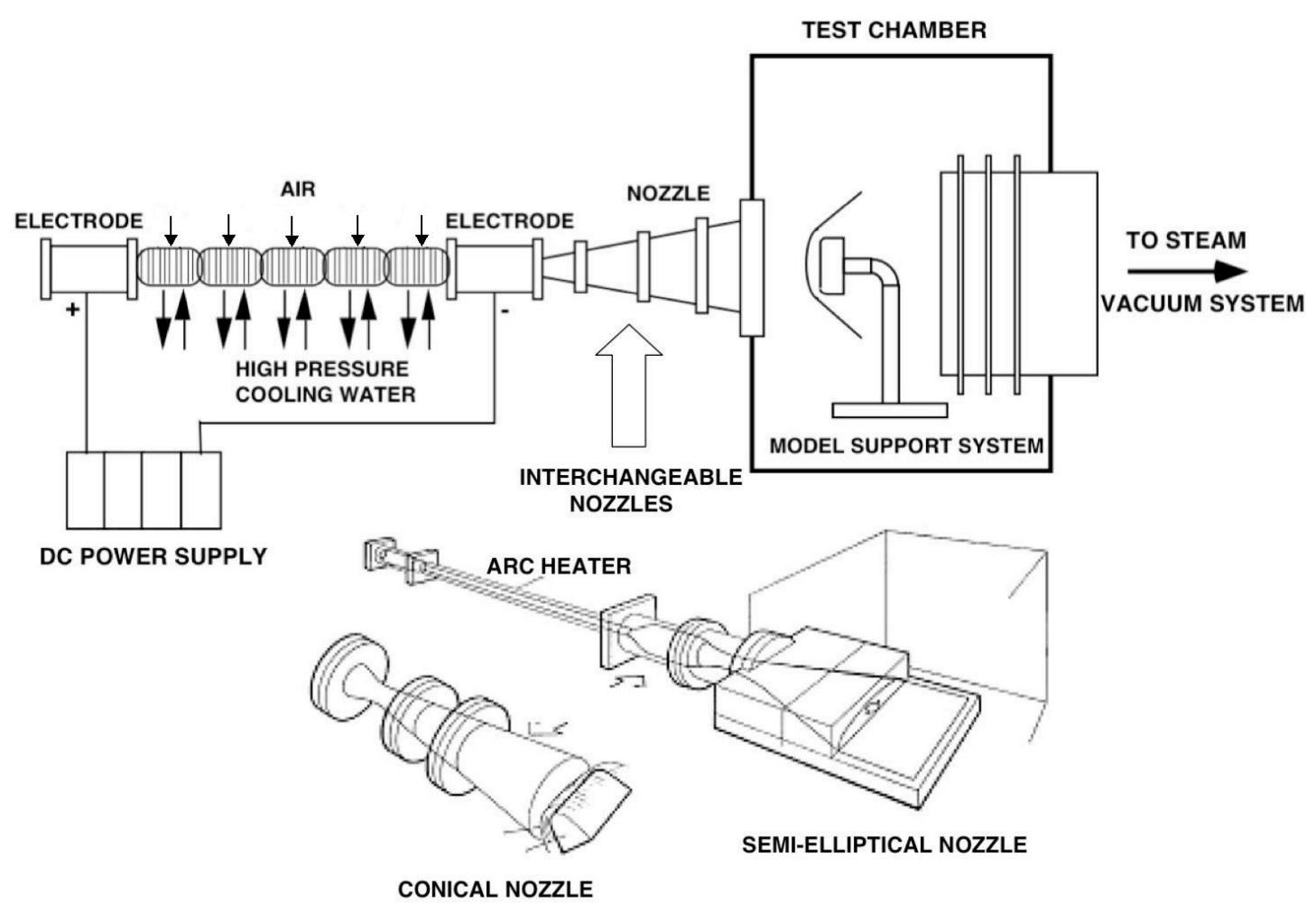

Fig. 1 Sketches of the NASA Ames 60-MW Interaction Heating Facility and its interchangeable nozzle configurations.

grid is generated using the ablated surface, and a new CFD solution on this grid is computed. The heating and pressure distributions used in the material response model are updated, and the procedure is repeated until the prescribed test time is reached. The total number of iterations depends on the total surface recession.

In the paper, effects of the shape change on fluid and material response simulations are demonstrated for arc-jet wedge models, and computational predictions of surface recession, shape change, and in-depth temperatures are compared with the experimental measurements.

\section{Arc-Jet Facility and Test Data}

NASA ARC has several arc-jet facilities within its Arc-Jet Complex. Of these, the 60-MW Interaction Heating Facility (IHF) has the highest power rating. Figure 1 shows a schematic diagram of the IHF and its nozzle configurations. The IHF consists of a constricted arc heater, a 60-MW DC power supply, interchangeable conical and semi-elliptical nozzles, a test box or chamber, and supplementary systems, including a steam ejector vacuum system, a cooling-water system and a data acquisition system. The IHF is designed to operate with a set of conical nozzles or a semi-elliptical nozzle at total pressures of 1-9 atm and total enthalpies of $7-47 \mathrm{MJ} / \mathrm{kg}$ (air). ${ }^{1-5}$ The $60-\mathrm{MW}$ constricted arc heater produces high-temperature test gas for both nozzles. The conical nozzle configurations of the IHF are suitable for tests of stagnation coupon and blunted wedge test articles, while the semi-elliptical nozzle configuration is designed mainly for testing flat panels in boundary-layer heating environments. Further information on the Ames IHF and other arc-jet facilities can be found in Refs. 1-5.

For the present paper, the wedge tests conducted using the IHF 6-inch diameter conical nozzle (IHF 193 test series) are considered. The nozzle has a throat diameter of $6.033 \mathrm{~cm}(2.375 \mathrm{in})$, and the diverging section of the nozzle has a half-angle of $10^{\circ}$ with an exit diameter of $15.24 \mathrm{~cm}(6 \mathrm{in})$. It should 


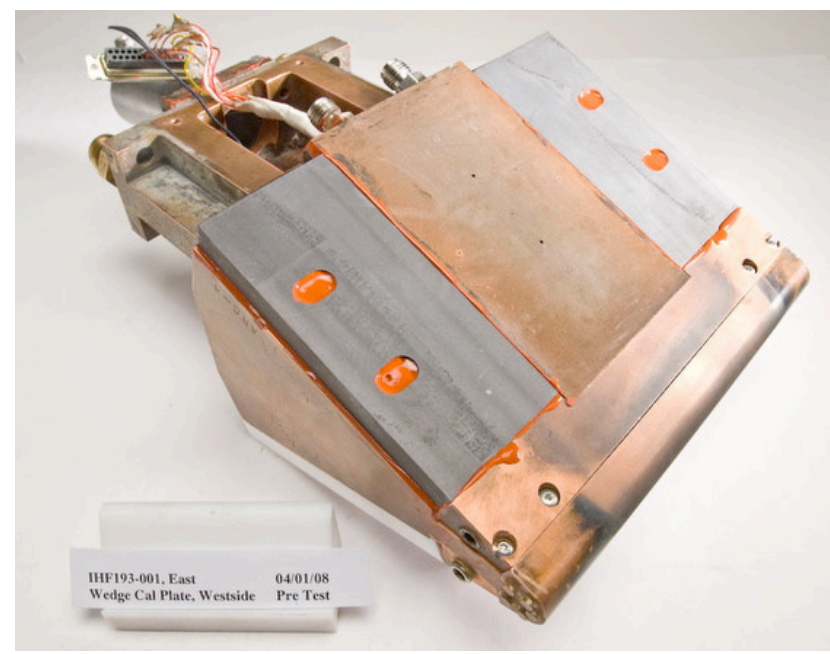

a)

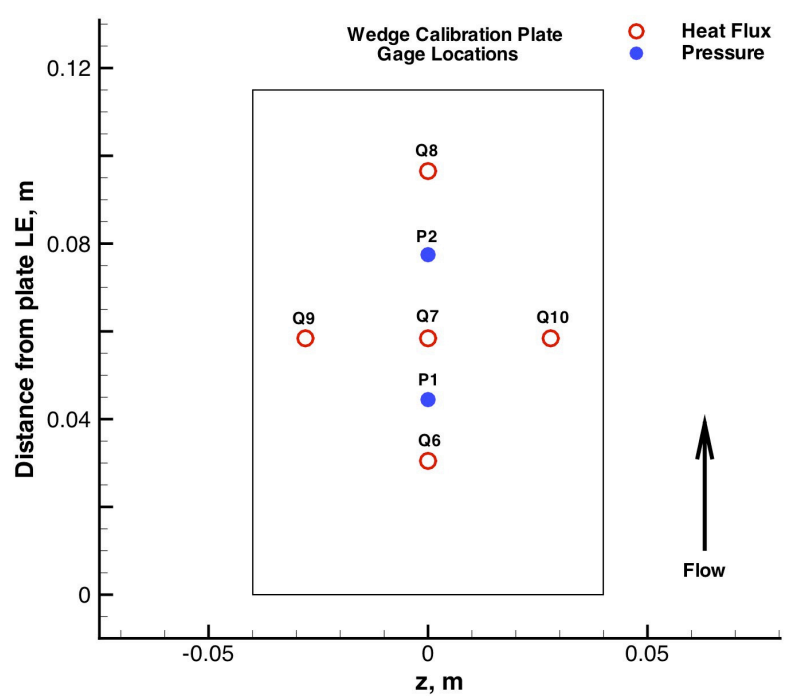

b)

Fig. 2 Wedge test calibration: a) a photograph of the water-cooled copper wedge model with the calibration plate; and b) locations of heat flux gages and pressure transducers.

also be noted that the IHF 6 -inch nozzle includes a $40^{\circ}$ extension piece $(4.6 \mathrm{~cm}$ long) attached to the nozzle exit. The blunt wedge model holders used in these tests were designed and fabricated by Henry Moody at Thermal Technologies Inc. ${ }^{20}$ The wedge holders are made of copper, water-cooled, and they can accommodate either a calibration plate or a TPS sample plate for testing. The calibration plates were instrumented with 5 Gardon gage calorimeters and 2 pressure transducers. For the tests considered, all wedge models were tested at $7.62 \mathrm{~cm}$ downstream of the nozzle exit and placed on the facility centerline. Figure 2 shows a photograph of the calibration plate mounted on the wedge model, with the heat flux calorimeter and pressure gage locations on the plate shown on the right. The PICA wedge tests (IHF 193 series) were run in order to evaluate performance of PICA at heating conditions with shear. The test data for the two PICA models include surface temperature, surface recession and in-depth (thermocouple) temperature measurements. The model surface temperatures were measured using one-color (Mikron M190H: 0.78-1.06 $\mu \mathrm{m}$ ) and two-color (Mikron M190 R2: 0.78-1.06 $\mu \mathrm{m}$ and 0.9-1.06 $\mu \mathrm{m}$ ) pyrometers. The PICA test articles included a thermocouple plug $5.588 \mathrm{~cm}$ from the plate leading edge, which had four in-depth thermocouples. The recession profiles were measured manually and by use of laser scans of the pre- and post-test models. The centerline total enthalpy of the arc-jet test flow was determined by CFD analysis along with the stagnation-calorimeter and calibration plate measurements. ${ }^{9}$

\section{Computational Approach}

Building blocks of the present computational analysis are: (1) steady-state CFD simulation of nonequilibrium expanding flow in the IHF nozzle and supersonic jet, and flowfield around arc-jet test articles; and (2) the material response simulation of the test article. The flowfield and material simulations are loosely coupled to take into account effects of the shape change of ablating test articles.

\section{A. Flowfield Simulation}

The Data Parallel Line Relaxation (DPLR) $\operatorname{code}^{21,22}$ is used for computations of the nonequilibrium flow in the nozzle and flowfield around test articles. DPLR has been used extensively at Ames for hypersonic flight and planetary entry simulations, and its results have been compared favorably against a wide variety of flight and ground-based experiments. DPLR provides various options for thermophysical models and formulation. For CFD calculations presented in this paper, both axisymmetric and twodimensional Navier-Stokes equations, supplemented with the equations accounting for nonequilibrium kinetic processes, are used in the formulation. The present thermochemical model for arc-jet flow includes 


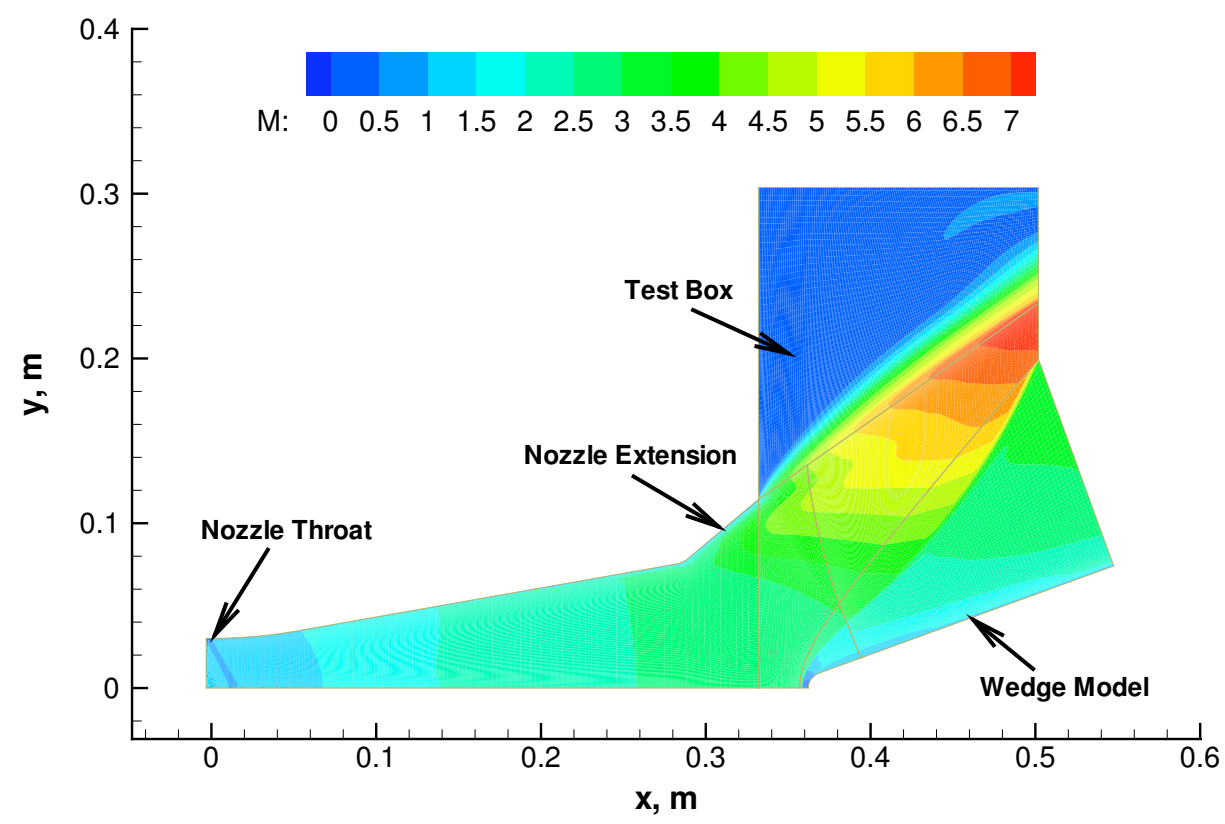

a) Mach number contours
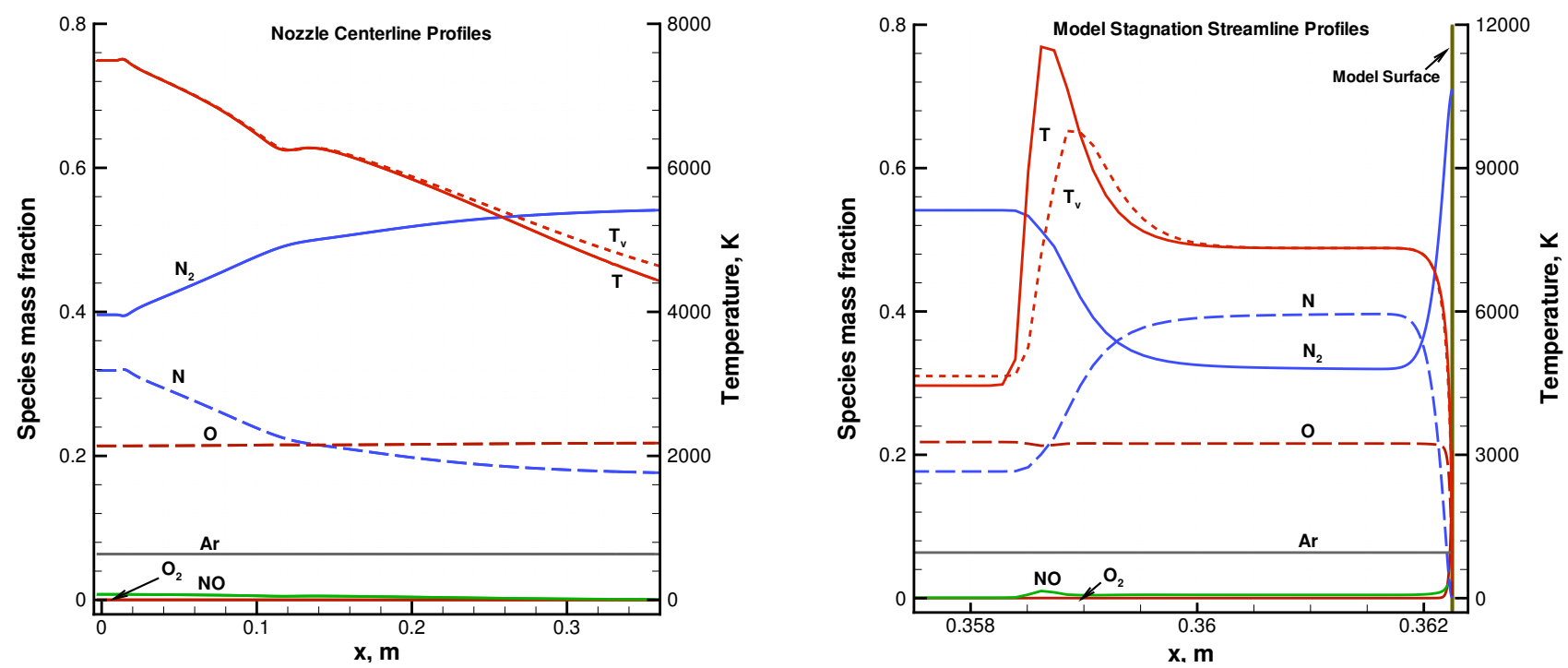

b) Flow properties along the nozzle centerline and model stagnation streamline

Fig. 3 Computed IHF 6-inch diameter nozzle flow downstream of the throat and flowfield over a wedge model: $p_{o}=890 \mathrm{kPa}, h_{o}=26.3 \mathrm{MJ} / \mathrm{kg}, \mathrm{p}_{\mathrm{box}}=2 \mathrm{torr}$, with $6.4 \%$ Ar in air

six species $\left(\mathrm{N}_{2}, \mathrm{O}_{2}, \mathrm{NO}, \mathrm{N}, \mathrm{O}, \mathrm{Ar}\right)$, and the thermal state of the gas is described by two temperatures within the framework of Park's two-temperature model. ${ }^{23,24}$ In the two-temperature model, excitations of internal degrees of freedom are divided into two classes, and it is assumed that excitations are equilibrated within each class. The translational and rotational modes of energy make up one class, and it is characterized by a translational-rotational temperature, $T$. The vibrational and electronic modes form the other class, and it is characterized by a vibrational-electronic temperature, $T_{v}$.

The flowfield in an arc-jet facility, from the arc heater to the test section, is a very complex, threedimensional flow coupled to various nonequilibrium processes. In order to simulate the flowfield, several simplifying assumptions are made, and corresponding numerical boundary conditions are prescribed for CFD simulations. The present nozzle simulations are started from the nozzle throat, and the flow 
properties at the throat are assumed to be those at thermochemical equilibrium. The total enthalpy of the arc-jet test flow (and its distribution) is usually inferred from facility and calibration measurements. For the present CFD simulations, the total enthalpy level and its distribution is set such that the computations reproduce the facility and calibration data as well as possible. The facility data include measurements of total pressure (arc-heater pressure), mass flow rate, total bulk enthalpy, test box pressure, and stagnation-point calorimeter heat flux and pitot pressure, while the calibration plate data include surface heat flux and pressure measurements. The present paper relies on the analysis of the wedge calibration data obtained in the IHF 6 -inch nozzle tests, ${ }^{9}$ and it uses the total enthalpy estimates obtained in Ref. 9 for simulations. Unless otherwise stated, all flow simulations in the facility and over the wedge model assume laminar flow. However, for the wedge model, turbulent flow simulations were also performed using the algebraic Baldwin-Lomax turbulence model. ${ }^{25}$

As an illustration of a typical wedge test simulation, Fig. 3 shows computed Mach number contours of the IHF 6-inch conical nozzle flow with a wedge model placed $7.62 \mathrm{~cm}$ downstream of the nozzle exit. Note that the IHF 6 -inch nozzle includes a 4.6 - $\mathrm{cm}$ long $40^{\circ}$ extension piece attached to the nozzle exit. The expansion waves emanating from the nozzle exit and from the corner of the extension piece connected to the test box are clearly observed in the computed Mach number contours. Generally, due to the nonequilibrium expansion process in arc-jet nozzles, the chemical composition freezes near the throat where the flow is dissociated and and vibrationally excited. However, for this condition in the 6-inch nozzle (at relatively high arc-heater pressure), the computations predict that the flow is in chemical and vibrational nonequilibirium but it is not frozen before it reaches the nozzle exit, as shown in Fig. $3 \mathrm{~b}$. Also, note that oxygen remains fully dissociated within the entire flowfield except in the boundary layer near the walls, while nitrogen is partially dissociated.

Although three-dimensional CFD simulations were performed to analyze the wedge calibration data in Ref. 9, for the present work, a combination of axisymmetric and two-dimensional simulations are performed (see Fig. 3a). For the conical nozzle and test box flowfield, axisymmetric simulations are performed, and for the wedge model flowfield, two-dimensional simulations are performed (see Fig. 3a). This simplification has been introduced to be able to couple the flowfield analysis to a material response model along the centerline of the wedge.

\section{B. Material Response Simulation}

The Two-Dimensional Implicit Thermal Response and Ablation Program (TITAN) ${ }^{26}$ is used for computing the material response of the test articles. In TITAN, the two-dimensional energy conservation equation, a three-component decomposition model, and the surface energy balance are solved with a moving grid to predict the thermal response and surface recession of charring materials. The internal energy equation is a transient thermal conduction equation with additional terms due to convection of the pyrolysis gas. The three-component solid model for organic resin composites consists of a general mixture of a two-component resin and a reinforcing material. Each of these components decomposes independently by a reaction rate. Virgin (original) and char (residual) density and thermal properties of each component are specified as functions of temperature, pressure, and orientation (for conductivity only). Thermochemical conditions at the ablating surface are determined by the aerothermal flow environment and by chemical interactions between the boundary layer gas, the pyrolysis gas, the ablation products, and the chemical constituents of the surface material. TITAN employs a convective transfercoefficient form of the surface energy balance to determine the surface conditions, and uses a blowing correction to account for the reduction in heat transfer coefficient (predicted by CFD) due to the injection of gases from pyrolysis and surface ablation. TITAN has also been used extensively at Ames for various simulations of hypersonic flight, planetary entry and arc-jet experiments. ${ }^{13,14,18,19,27,28}$

For material thermal response simulations in this paper, a two-dimensional representation of the wedge model holder is employed. For all PICA material response simulations, the PICAv3.3 material property model developed by Milos and Chen ${ }^{26,29}$ is used. For the water-cooled section of the wedge, the copper properties in the TPSX database ${ }^{30}$ are used. Figure 4 shows the material map used for the wedge copper section and PICA plate in the simulations and a photograph of the wedge model holder with the PICA plate. For thermal response simulations, the back surface of the PICA panels is assumed 


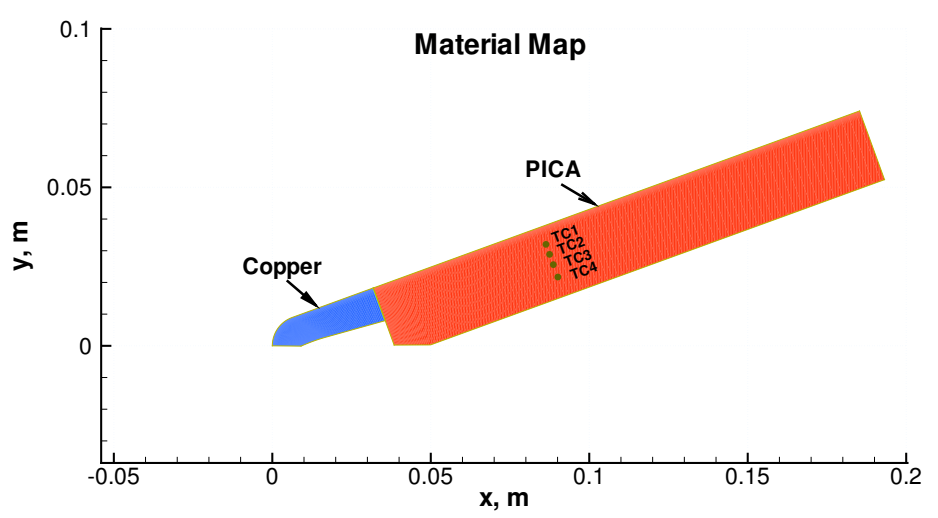

a)

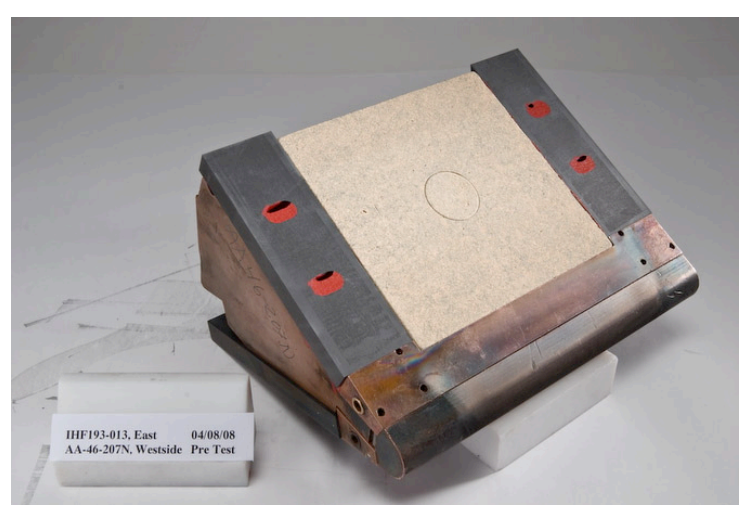

b)

Fig. 4 The material map used for material response simulations and a photograph of the wedge model holder with the PICA plate including a plug with in-depth thermocouples at the center.

to be insulated, and the back surface of the copper section is assumed to be at the room temperature. In order to make accurate in-depth temperature predictions of the test article and to make comparisons with the test data, the tested PICA panel thickness of $2.337 \mathrm{~cm}$ is duplicated in the material response simulations.

\section{Fluid and Material Response Coupling}

The DPLR and TITAN simulations are loosely coupled. In this approach, the simulation is started with the unablated shape and the corresponding heat flux and pressure distributions. When a predetermined recession level predicted by TITAN is reached at any location on the model, a new CFD solution using a new grid for the ablated shape is computed. The heat flux and pressure distributions used in TITAN are updated, and the procedure is repeated until the prescribed test time is reached. CFD simulations are performed using fully catalytic cold wall boundary conditions. Only distributions of the surface heat flux $\left(q_{w}\right)$ or the heat transfer coefficient $\left(C_{H}\right)$, the surface pressure $\left(p_{s}\right)$ and total enthalpy $\left(h_{\circ}\right)$ estimated by CFD simulations are fed into each TITAN run. The TITAN simulation provides predictions of the surface temperature and recession, and the intermediate surface coordinates to

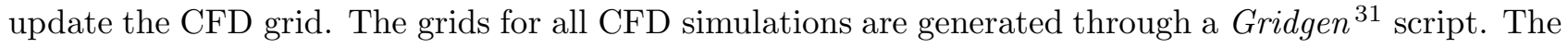
entire simulation (DPLR, TITAN and Gridgen) is performed using a UNIX shell script that executes the specified number of iterations. For the present simulations, the model surface and subsequent CFD simulations are updated whenever the maximum recession in the TITAN simulation reaches $0.05 \mathrm{~mm}$. This means that for a $1 \mathrm{~cm}$ total recession at any location on the model, approximately 200 Gridgen, DPLR and TITAN simulations would be performed.

\section{Presentation of Computed Results}

Results of the computational simulations for two cases from the IHF 193 tests are presented. First, effects of the test article shape change on the flowfield and material response simulations are presented. Second, an example of a nonuniform total enthalpy profile simulation and its effects on the surface heat flux and recession are presented. Finally, the results of both laminar and turbulent flow simulations and comparisons with experimental measurements are presented.

The arc-jet data and the computational predictions for two arc-jet conditions are summarized in Table 1. The three-dimensional CFD predictions of the test environment parameters from Ref. 9 are also included in Table. 1. Note that the CFD predictions of the surface quantities are given as a range, from the leading edge to the trailing edge of a 10.16-cm-long wedge plate, while the measured calibration plate heat flux and pressures are listed at specific gage locations only. The pressure taps $p_{1}$ and $p_{2}$ are at $4.45 \mathrm{~cm}$ and $7.75 \mathrm{~cm}$ from the calibration plate leading edge, and the heat flux gages $Q_{6}, Q_{7}$, and $Q_{8}$ 
Table 1. Summary of the arc-jet data and computational predictions for $20^{\circ}$ wedge tests.

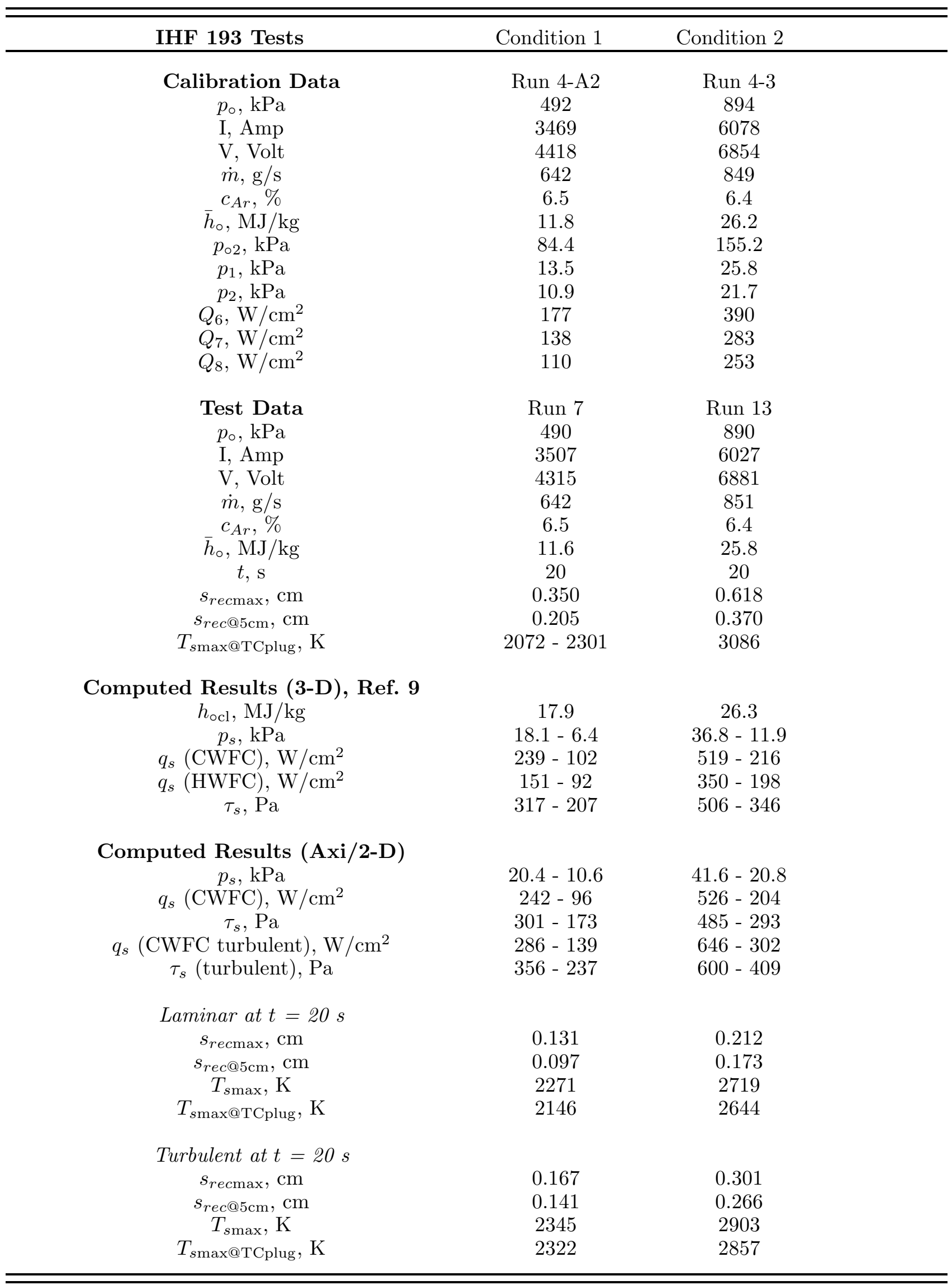



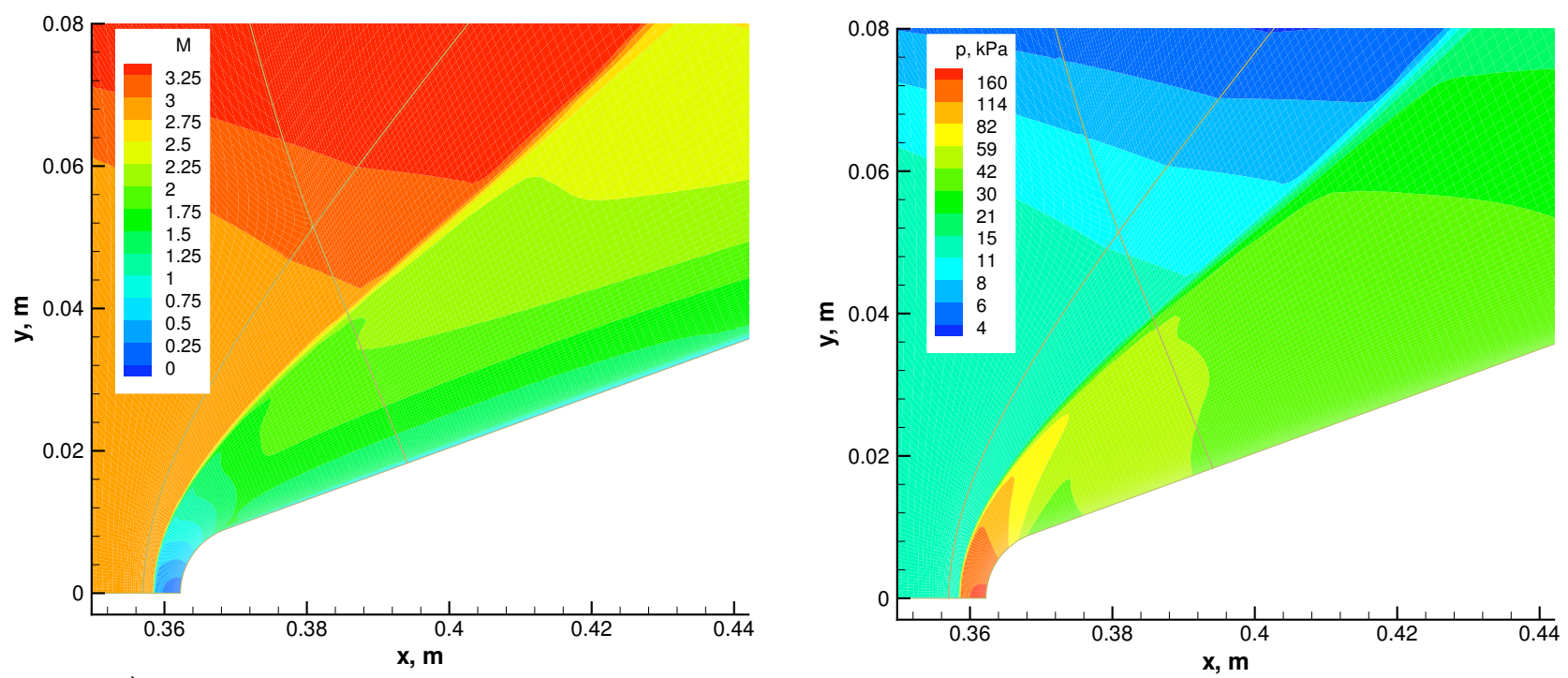

a) $\mathrm{t}=0 \mathrm{~s}$
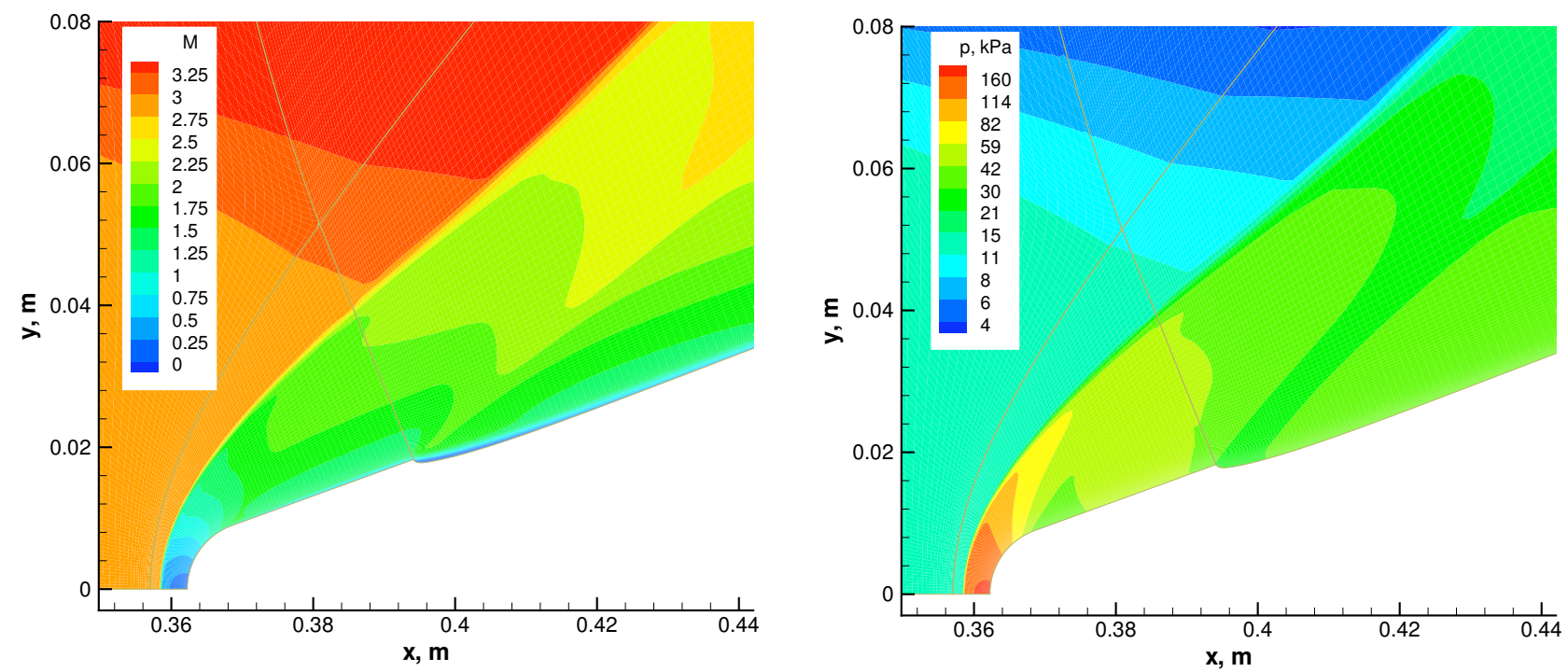

b) $\mathrm{t}=20 \mathrm{~s}$

Fig. 5 Computed Mach number and pressure contours of the wedge flowfield near the plate leading edge at two test times from Condition 2. IHF 6-inch nozzle flow: $p_{o}=890$ $\mathrm{kPa}, h_{o}=26.3 \mathrm{MJ} / \mathrm{kg}$, with $6.4 \% \mathrm{Ar}$ in air.

are at $3.05 \mathrm{~cm}, 5.84 \mathrm{~cm}$, and $9.65 \mathrm{~cm}$, respectively (see Fig. 2b). For each condition, computed results and comparisons with the test data are presented in the following sections.

\section{A. Effects of Shape Change on Flowfield and Material Response Simulations}

In this section, effects of the test article shape change on the flowfield and material response simulations are presented.

In Fig. 5, the computed Mach number and pressure contours of the wedge model are shown at two test times, $t=0$ and $20 \mathrm{~s}$ from Condition 2. As mentioned earlier, ${ }^{9}$ the expansion waves emanating from the nozzle exit (and the exit of the extension piece) to the test box ordinarily affect the shape and strength of the shock formed over the wedge model, hence significantly affecting the pressure distribution on the model. Significant pressure and Mach number variations in the freestream of the wedge flow are clearly seen in the contour plots. It should be noted that the scale of the pressure contours is logarithmic. These contour plots also show qualitatively how the flow over the test plate is altered by the shape change of the article at $t=20 \mathrm{~s}$. The supersonic flow expansion at the recessed plate leading edge and ensuing 


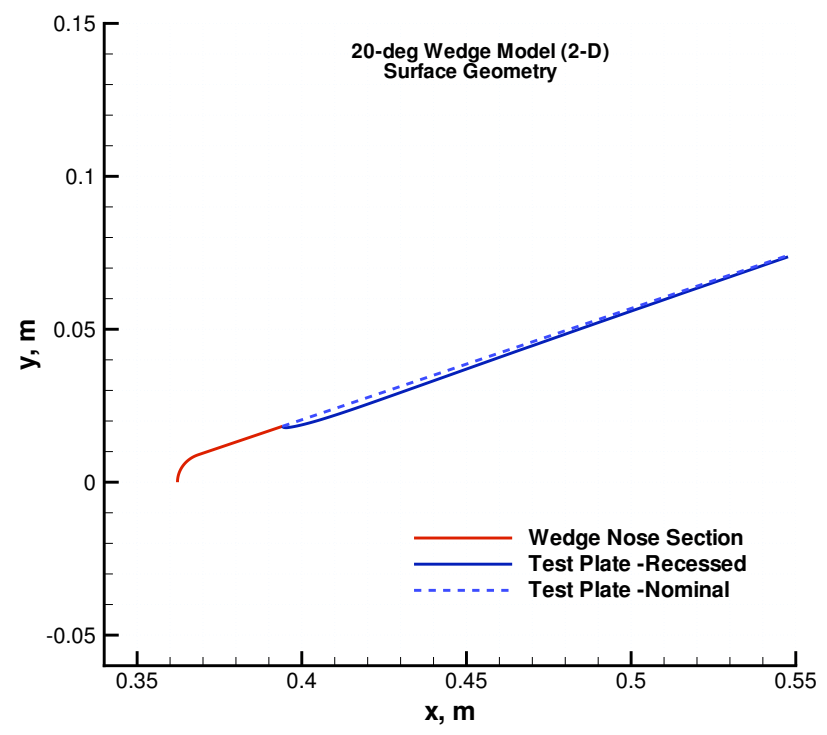

a) wedge geometry

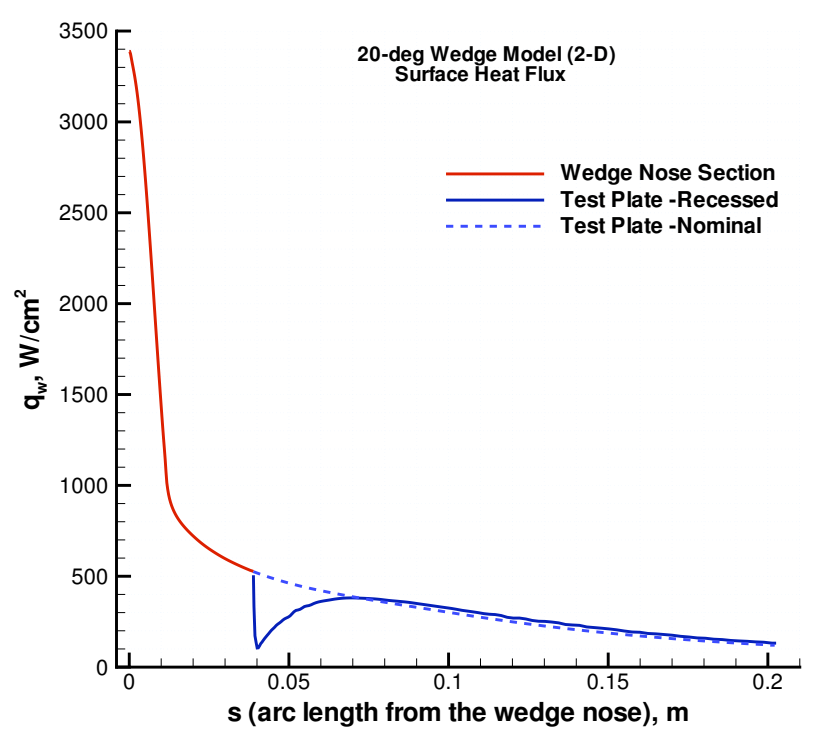

c) heat flux

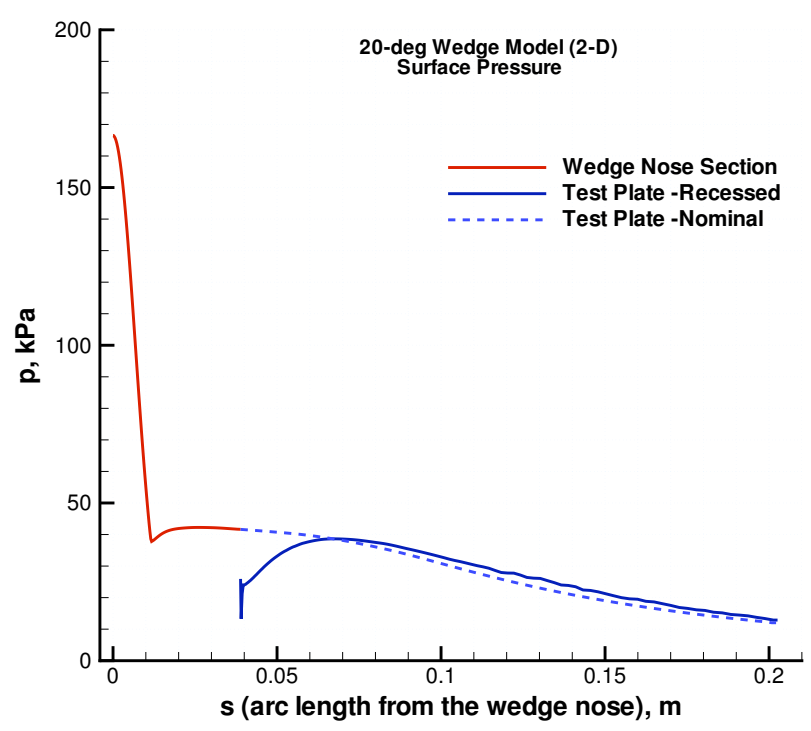

b) pressure

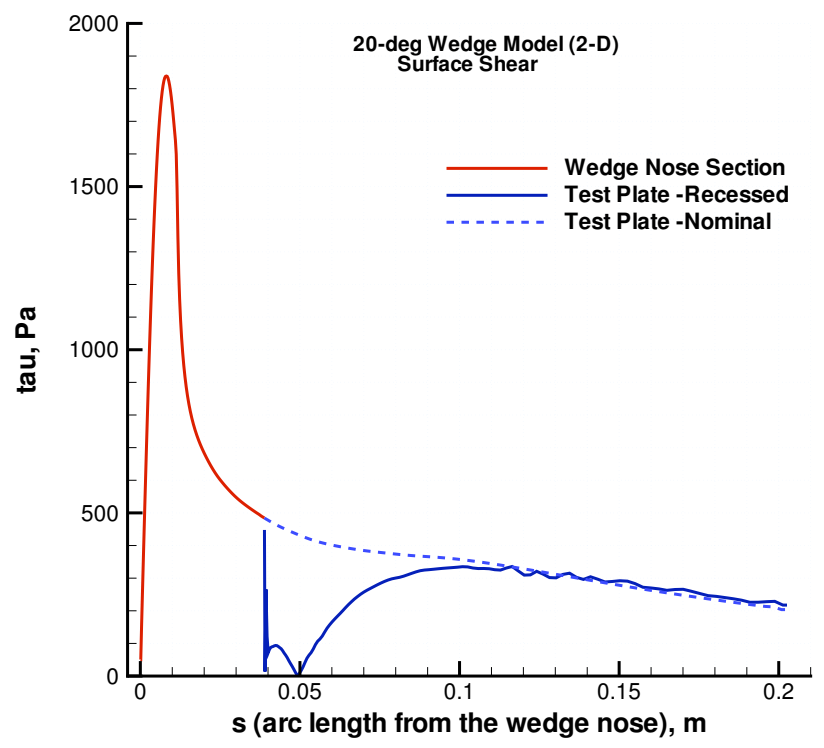

d) shear

Fig. 6 Comparisons of computed wedge geometry and surface quantities for Conditon 2 at two test times, $t=0 \mathrm{~s}$ and $t=20 \mathrm{~s}$. IHF 6-inch nozzle flow: $p_{o}=890 \mathrm{kPa}, h_{o}=26.3$ $\mathrm{MJ} / \mathrm{kg}$, with $6.4 \%$ Ar in air.

flow compression over the plate can be observed in the contour plots, Fig. 5b. The surface conditions on the plate are likely to be affected by these shape-change-related features in the flow.

In Fig. 6, comparisons of computed wedge geometry and surface quantities are presented at the same two test times, $t=0$ and $20 \mathrm{~s}$, from Condition 2. The nominal wedge geometry is compared with the recessed plate in Fig. 6a, and effects of shape change on the surface pressure, heat flux and shear are shown in Fig. 6b-d, respectively. As the PICA test plate starts to ablate, a cavity is formed near the plate leading edge (similar to a backward facing step). As a result, the computed heat flux, pressure and shear near the leading edge drop significantly in comparison with those on the unrecessed plate. As shown in Fig. 5b, the flow goes through a compression (downstream of the cavity), which causes the surface pressure and heat flux to overshoot the unrecessed values slightly. Most of the effects are near the plate leading edge, and these effects are likely to increase with increasing recession. 


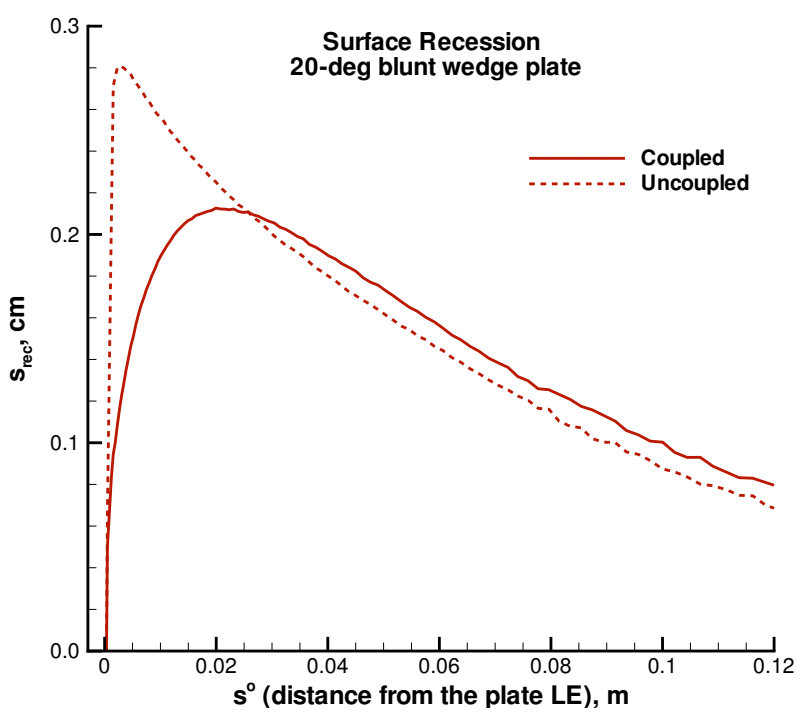

a) Surface recession

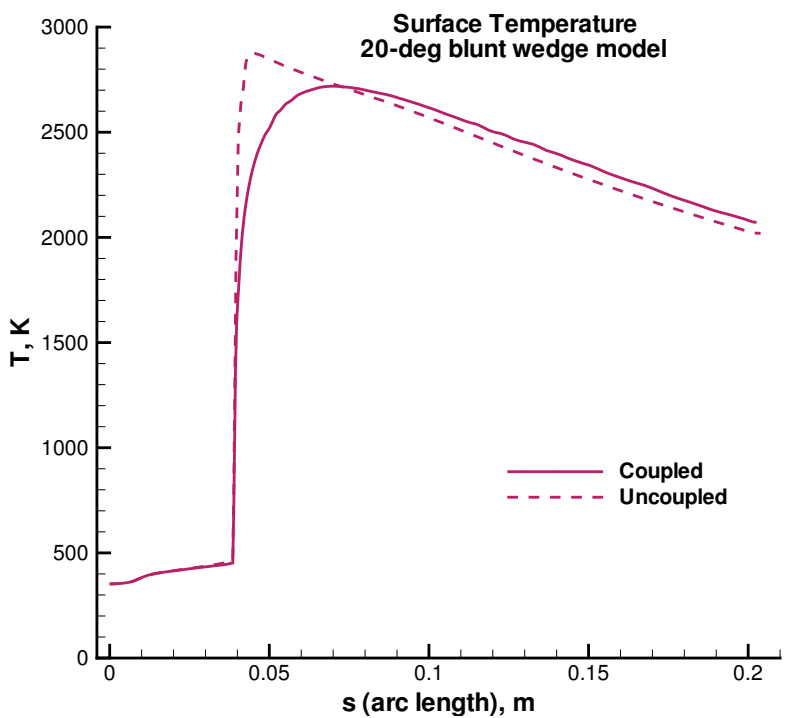

b) Surface temperature

Fig. 7 Comparison of coupled and uncoupled material response simulation results at $t=$ 20 s. IHF 6-inch nozzle flow: $p_{o}=890 \mathrm{kPa}, h_{o}=26.3 \mathrm{MJ} / \mathrm{kg}$, with $6.4 \% \mathrm{Ar}$ in air.

In Fig. 7, comparisons of coupled and uncoupled material response simulation results, surface recession and temperature, are presented at $t=20 \mathrm{~s}$. For the uncoupled TITAN simulations, the nominal heat flux and pressure distributions corresponding to the unablated shape are used for the entire test time of $20 \mathrm{~s}$. Since the decrease in the heat flux and pressure near the plate leading edge with time are not accounted for in the uncoupled simulations, the surface recession and temperature are overpredicted near the leading edge. As expected from the comparisons of surface quantities in Fig. 6, the effects of the shape change on the material response are also most pronounced near the leading edge of the plate, and for this case they are mostly limited to a $2.5-\mathrm{cm}$ region.

\section{B. Effects of Nonuniformity in Total Enthalpy Profile}

Even though the distribution of total enthalpy at the nozzle exit is not known experimentally (there are no heat flux calorimeter/pitot surveys available for these tests), simulations with varying degrees of nonuniformity, differentiated by the ratio of the centerline total enthalpy to the bulk enthalpy, show that the centerline total enthalpy is the most important parameter for predicting the heat flux distribution over the wedge model, as reported in Ref. 9. Figure 8 shows an example of a parabolic enthalpy profile and its effects on the surface heat flux at $t=0 \mathrm{~s}$ and on the surface recession at $t=20 \mathrm{~s}$. It should be noted that even though there is a significant variation in the total enthalpy profile, the boundary layer edge total enthalpy for the wedge model flowfield could be approximated by the centerline total enthalpy of the nozzle flow. For these cases, parabolic profiles at the throat are introduced. The distributions are varied by keeping the centerline mass flux and total enthalpy at the nozzle throat constant while changing the mass averaged bulk quantities. Noting that the uncertainty of the estimated centerline total enthalpy is within $\pm 15-20 \%$, the effects of a nonuniform enthalpy profile on the computed surface heat flux and surface recession can be considered secondary. However, it should also be mentioned that knowledge of the total enthalpy distribution would be very important if the wedge models were not tested on the facility nozzle centerline. For the tests considered in this paper, the wedge models were tested on the centerline.

\section{Laminar Simulations}

In this section, laminar flow simulation results and comparisons with the measured recession and in-depth temperatures for the two conditions are presented.

In Fig. 9, the computed temperature contours and surface temperatures of the wedge model for Condition 1 are shown at two test times, $t=0.5$ and $20 \mathrm{~s}$. At $t=0.5 \mathrm{~s}$, the model is still relatively cold. 


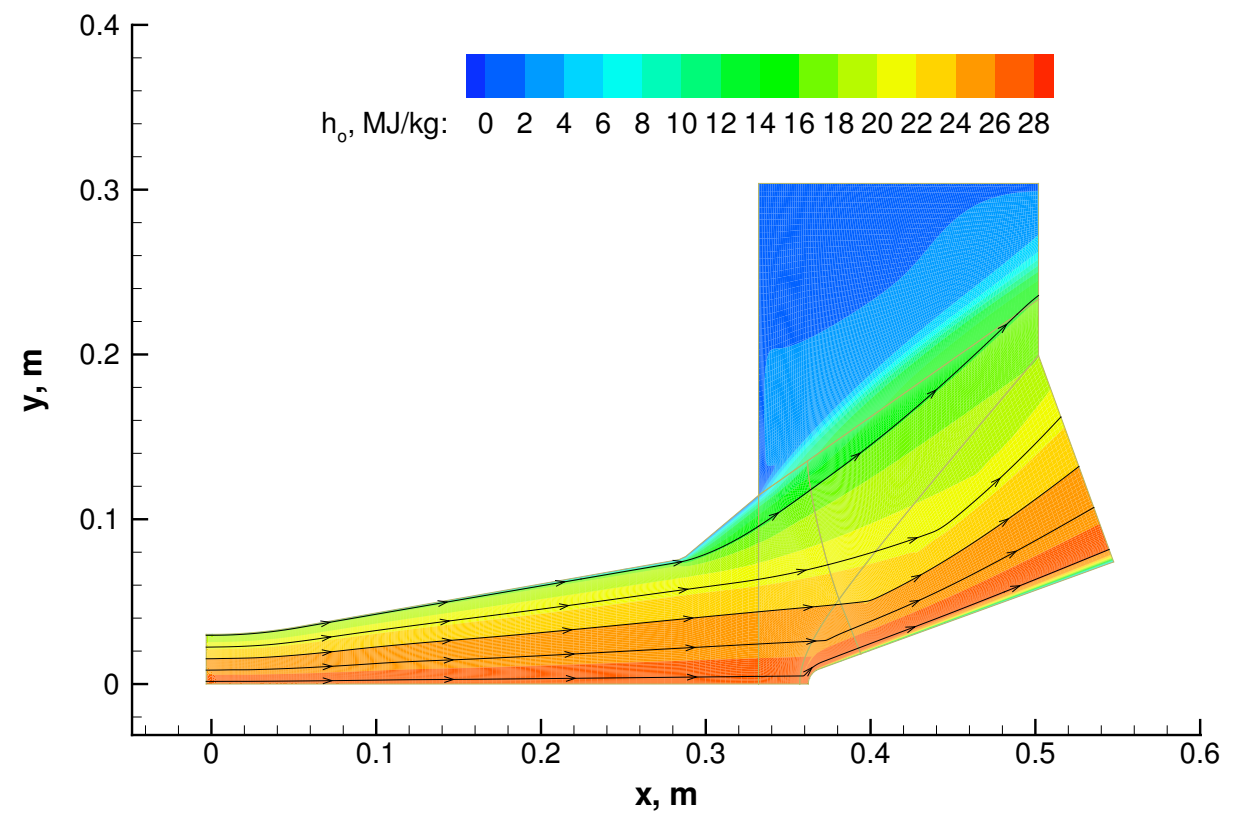

a) Total enthalpy contours, $h_{\circ \mathrm{ocl}} / \bar{h}_{\circ}=1.2$

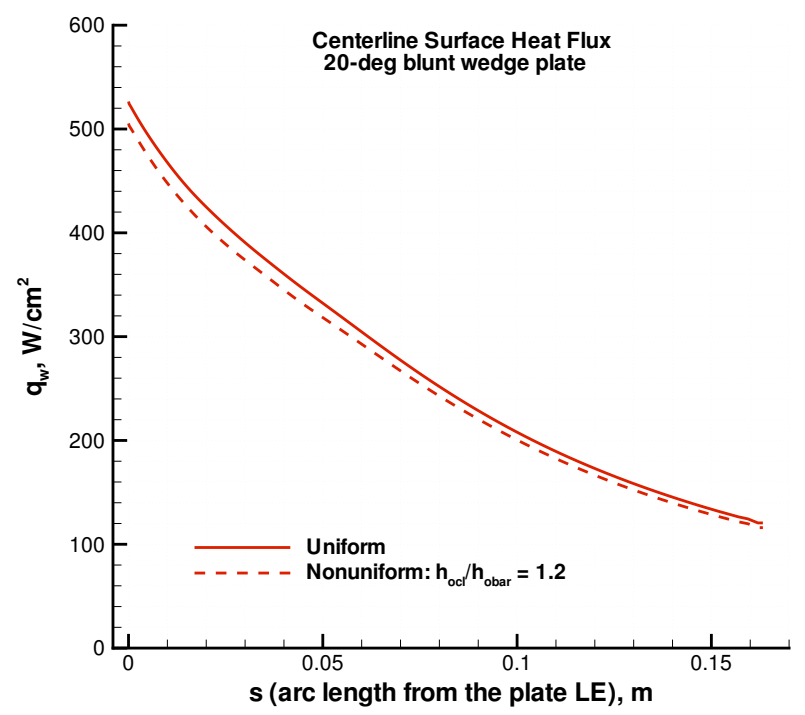

a) Surface heat flux $t=0 \mathrm{~s}$.

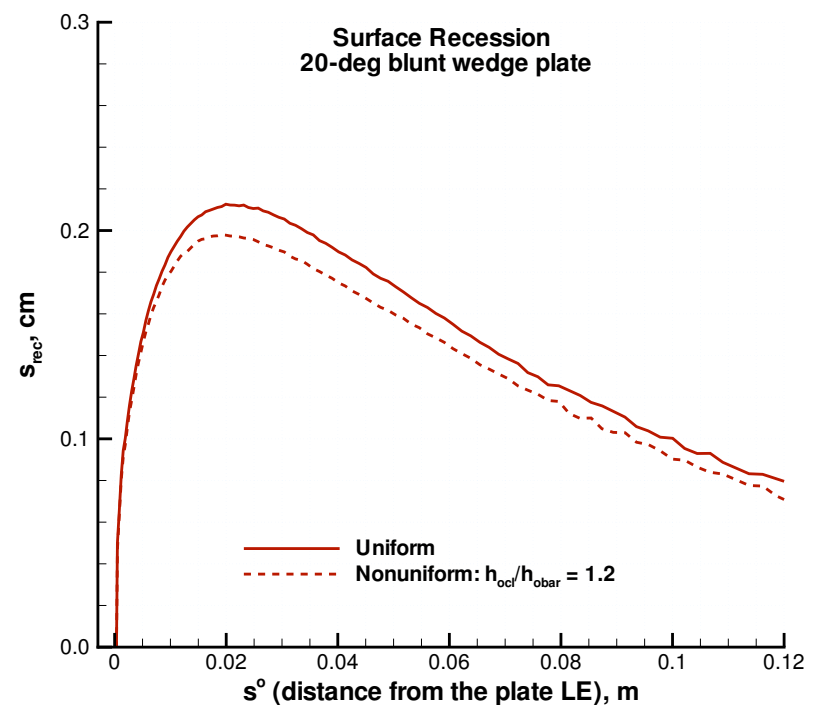

c) Surface recession profiles at $t=20 \mathrm{~s}$.

Fig. 8 Effects of a nonuniform total enthalpy profile at the nozzle throat on the computed wedge plate heat flux and recession. $p_{o}=890 \mathrm{kPa}, h_{o c l}=26.3 \mathrm{MJ} / \mathrm{kg}, \mathrm{p}_{\mathrm{box}}=2 \mathrm{torr}$, with $6.4 \%$ Ar in air

The temperature discontinuity at the leading edge of the test plate is due to two different materials, copper and PICA, having different emissivities and thermal conductivities. The surface temperature of the plate gradually increases with time, and as a result, the surface recession occurs. The heat penetration depth is clearly seen in the temperature contour plot. The maximum computed surface temperature for the PICA plate is $2271 \mathrm{~K}$.

Figure 10 shows comparisons of the computed recession profiles and in-depth temperatures with IHF 193 Run 7 measurements. For IHF 193 tests, the recession profiles were measured manually and by use of laser scans of the pre- and post-test models. The experimental data at these heating conditions 

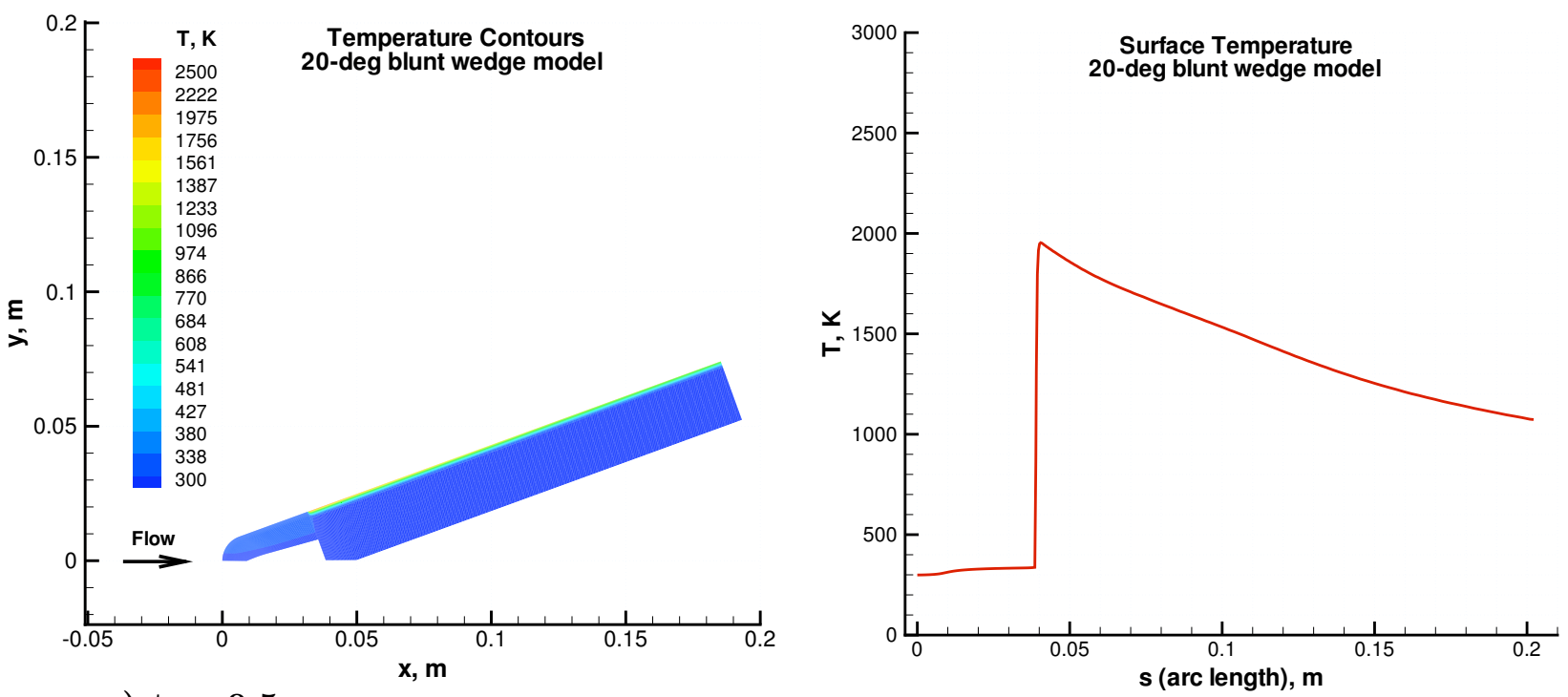

a) $\mathrm{t}=0.5 \mathrm{~s}$
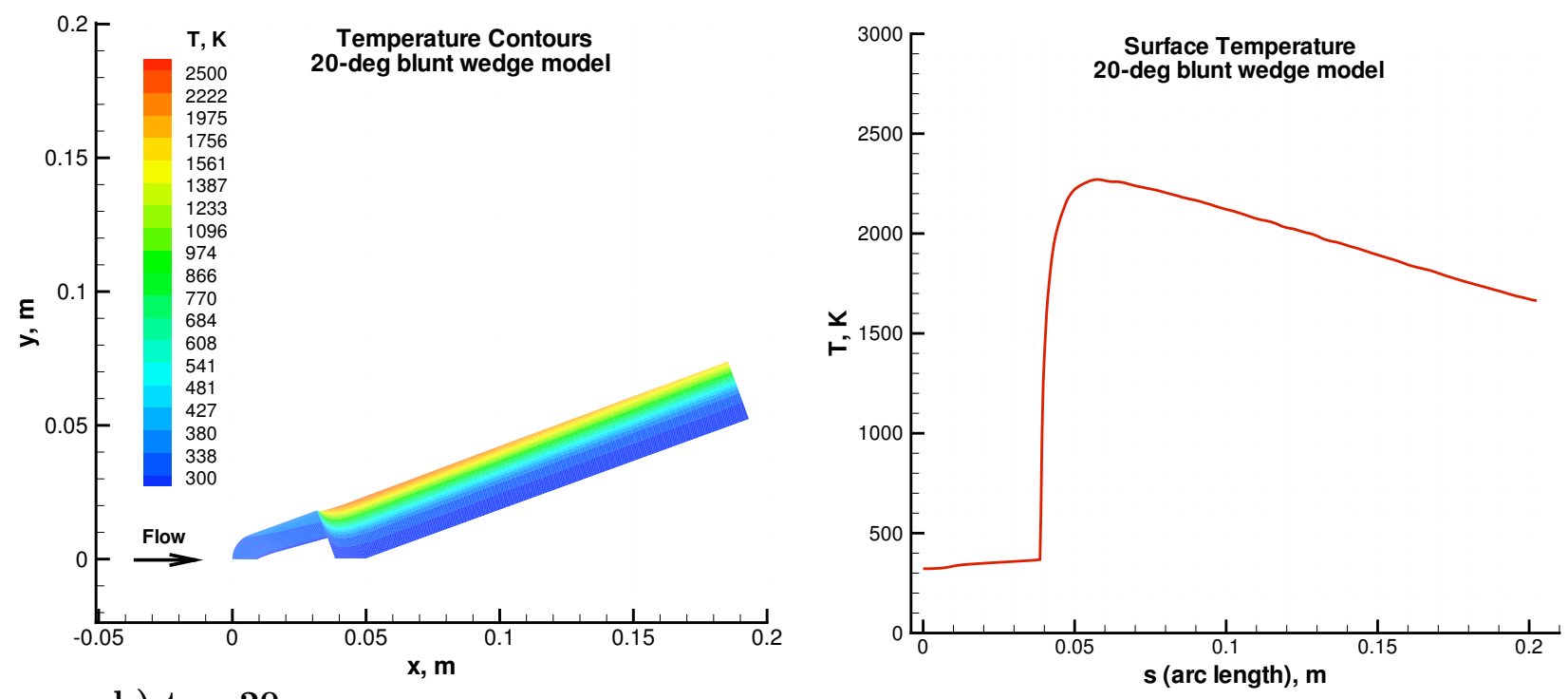

b) $\mathrm{t}=20 \mathrm{~s}$

Fig. 9 Computed temperature contours of the $20^{\circ}$ wedge model for Condition 1 at two test times and their surface profiles. IHF 6-inch nozzle flow: $p_{o}=490 \mathrm{kPa}, h_{o}=17.9$ $\mathrm{MJ} / \mathrm{kg}$, with $6.5 \%$ Ar in air.

(heat flux and pressure) show that the test time of $t=20 \mathrm{~s}$ is sufficient to cause the PICA material to ablate about $0.35 \mathrm{~cm}$. It should be noted that the shape of the recession profile is not monotonic: it rises rapidly starting from the plate leading edge and gradually decreases along the plate. The predicted profile is due to the material interface and the flowfield interaction caused by the recession. The gradual decrease in the recession profile is ordinarily due to the decrease in surface heat flux and pressure along the plate. Clearly, these computations significantly underpredict the recession of the PICA plate (by a factor of 2 or more). In Fig. 10b, computed in-depth temperatures are compared with thermocouple measurements. For IHF 193 Run 7, the thermocouple plug was $5.588 \mathrm{~cm}$ from the plate leading edge, and the thermocouples (TC1, TC2, TC3, TC4) were placed at depths of $0.630 \mathrm{~cm}, 0.897 \mathrm{~cm}, 1.273 \mathrm{~cm}$, and $1.659 \mathrm{~cm}$, respectively, from the surface. Although it is difficult to interpret the in-depth temperatures when the recession is significantly underpredicted, it is surprising that the computed temperatures are in reasonable agreement with TC1 measurements, yet they overpredicted the TC3 and TC4 measurements. 


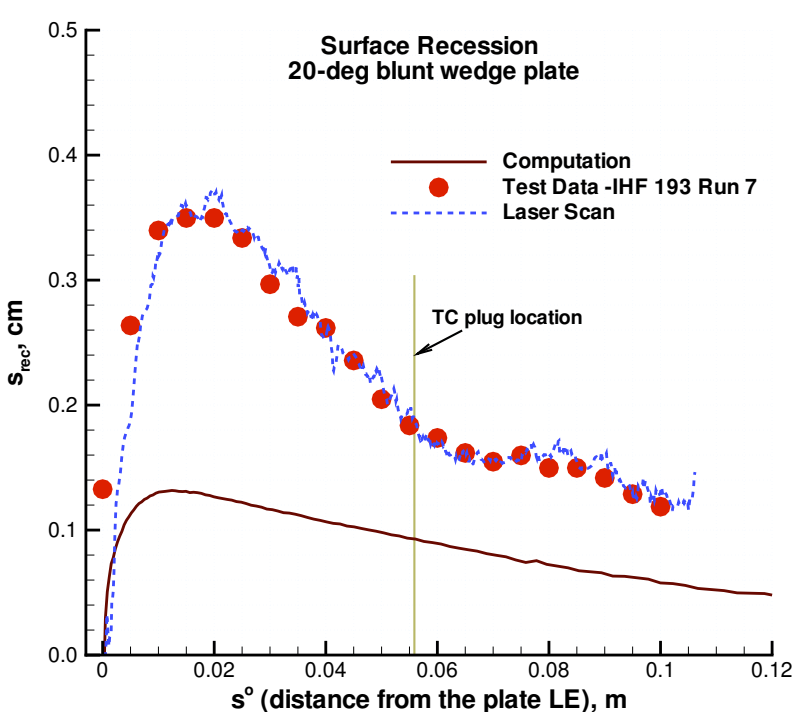

a) Surface recession at $t=20 \mathrm{~s}$

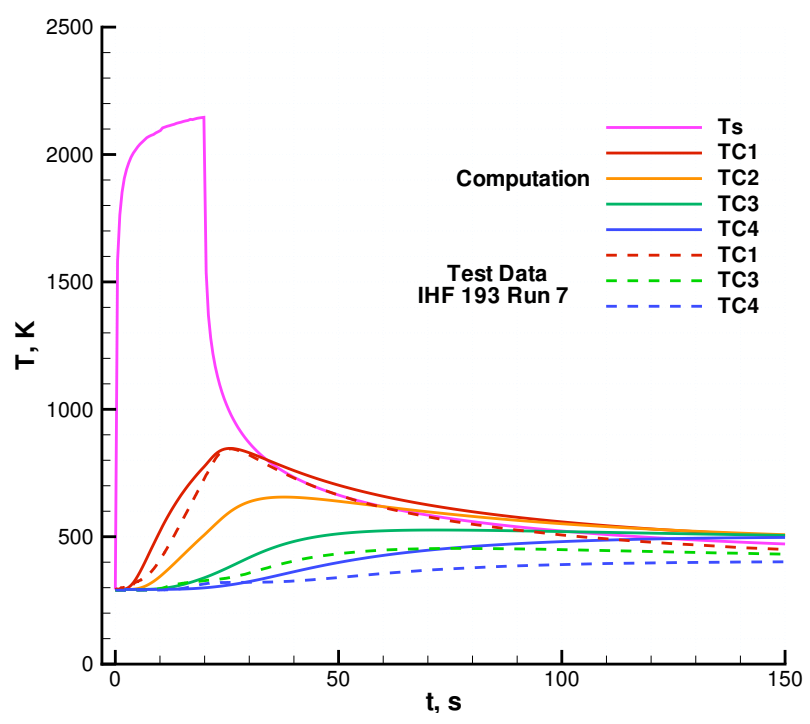

b) In-depth temperatures

Fig. 10 Comparisons of computed recession profiles and thermocouple response with the measurements at Condition 1. IHF 6-inch nozzle flow: $p_{o}=490 \mathrm{kPa}, h_{o}=17.9 \mathrm{MJ} / \mathrm{kg}$, with $6.5 \%$ Ar in air.

TC2 malfunctioned, so the TC2 data were not available for this test. Although the surface pyrometer temperatures are not generally as reliable as TC measurements, the model surface temperatures were also measured using one-color and two-color pyrometers. The maximum surface temperatures measured at the TC plug location with the two pyrometers were in the range of $2072-2301 \mathrm{~K}$ (the higher one is with the one-color pyrometer). The pyrometer temperatures reported in Table 1 include corrections for window losses and PICA emissivity $(\epsilon=0.931)$. The computed maximum surface temperature at the TC plug location is $2146 \mathrm{~K}$. The fact that the predicted surface temperature is in reasonable agreement suggests that the computed heating levels should be close to those experienced by the test article.

Underprediction of the recession implies that a significantly higher mass transfer coefficient would be needed in the computational model to be able to reproduce the measured recession. For these simulations, the recovery enthalpy of the wedge flow was set equal to the centerline total enthalpy of the arc-jet flow. One way to increase the heat transfer (and mass transfer) coefficient is by reducing the recovery enthalpy. Simulations were also performed by setting the recovery enthalpy to $90 \%$ of the centerline total enthalpy, which in turn increases the heat transfer and mass transfer coefficients. The predicted maximum recession was then increased by approximately $11 \%$ (not shown here). Currently, the effect of unequal heat and mass transfer coefficients can not be easily assessed in TITAN.

Figure 11 presents the computed temperature contours and surface temperatures of the wedge model at Condition 2 for two test times, $t=0.3 \mathrm{~s}$ and $t=20.2 \mathrm{~s}$. Similar to Fig. 9 , at $t=0.3 \mathrm{~s}$, the model is initially relatively cold. The time $t=20 \mathrm{~s}$ represents the end of the test, after which the ablated model starts to cool down. The maximum computed surface temperature for the PICA plate is $2719 \mathrm{~K}$.

Figure 12 shows comparisons of the computed recession profiles and in-depth temperatures with the IHF 193 Run 13 measurements. As in Fig. 10a, Fig. 12a also shows that the computations significantly underpredict the recession of the PICA plate. The computed and measured recesssion values are tabulated in Table 1. However, the comparison of computed and measured in-depth temperatures in Fig. 12b indicates trends different from those of Fig. 10b. For IHF 193 Run 13, the thermocouple plug was again $5.588 \mathrm{~cm}$ from the plate leading edge, and the thermocouples (TC1, TC2, TC3, TC4) were placed at depths of $0.572 \mathrm{~cm}, 0.907 \mathrm{~cm}, 1.252 \mathrm{~cm}$, and $1.669 \mathrm{~cm}$, respectively, from the surface. The computations underpredict the TC1 and TC2 measurements while they are in reasonable agreement with the TC3 and TC4 measurements. The maximum surface temperatures measured at the TC plug location with two different pyrometers were in good agreement at $3086 \mathrm{~K}$. The computed maximum surface temperature 

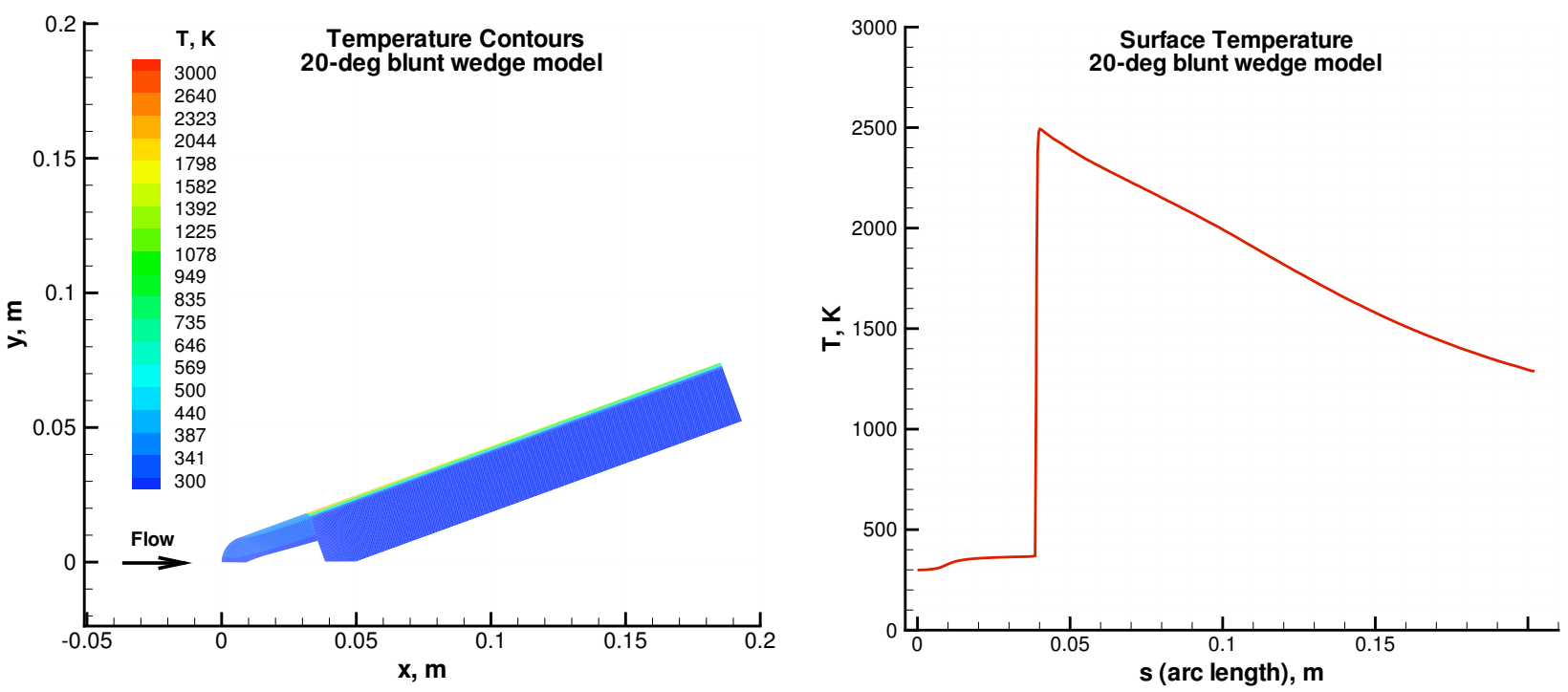

a) $\mathrm{t}=0.3 \mathrm{~s}$
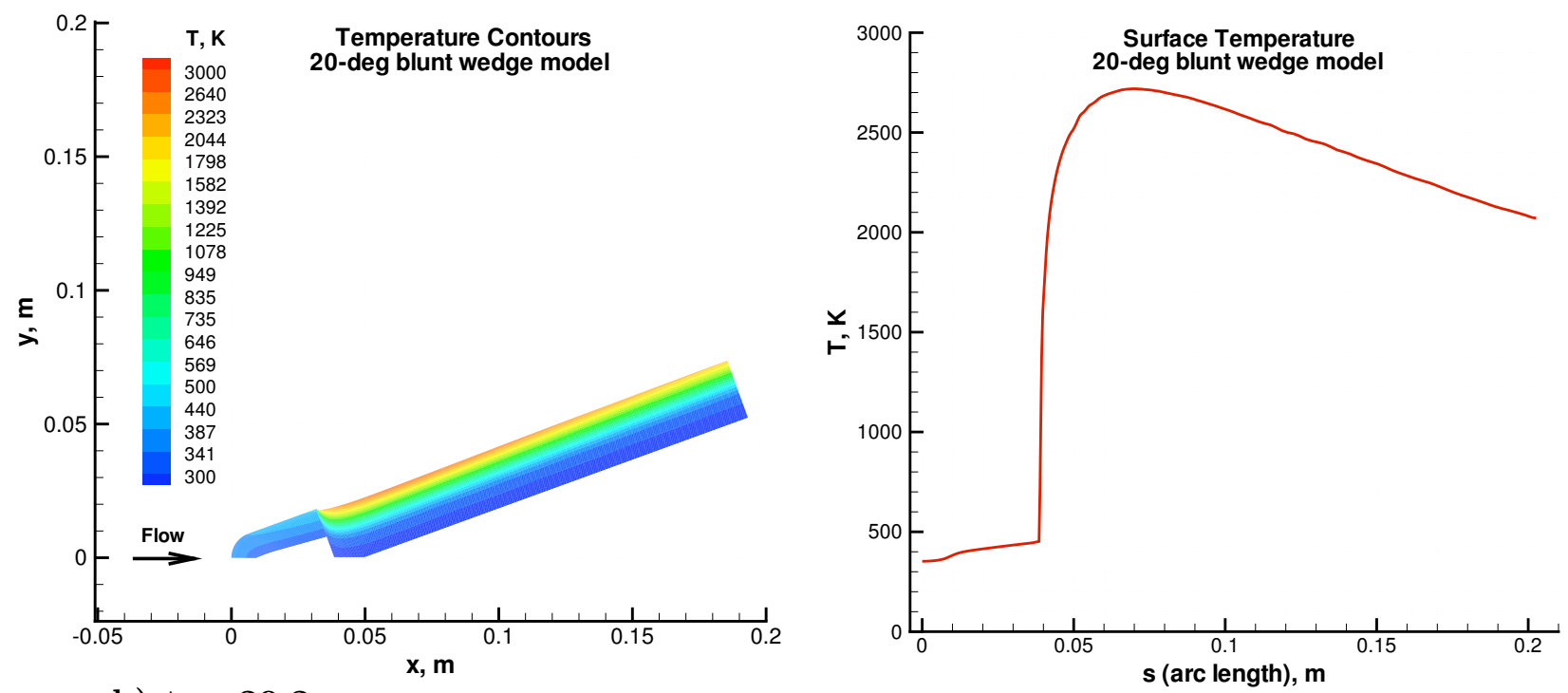

b) $\mathrm{t}=20.2 \mathrm{~s}$

Fig. 11 Computed temperature contours of the $20^{\circ}$ wedge model at two test times and their surface profiles at Condition 2. IHF 6-inch nozzle flow: $p_{o}=890 \mathrm{kPa}, h_{o}=26.3$ $\mathrm{MJ} / \mathrm{kg}$, with $6.4 \%$ Ar in air.

at the TC plug location is $2644 \mathrm{~K}$. The fact that both recession and in-depth thermocouple temperatures are underpredicted indicates that both mass and heat transfer are underpredicted in the computations. Also, the predicted surface temperature and near-surface TCs are significantly lower than the measurements, which suggest that the predicted heat flux levels on the test article are also lower than those during the test.

\section{Turbulent Simulations}

Even though the calibration plate data were reproduced with the CFD simulations assuming that the flow over the calibration plate was laminar, there are a few reasons to perform turbulent simulations. It is plausible that the flow over the test articles may have transitioned to turbulent flow due to the surface roughness, which occurs as a result of ablation. Figure 13 shows post-test photographs of the PICA samples on the wedge model. The surfaces of the test articles appear to be relatively rough after the test, although the surface roughness has not been characterized in terms of roughness distribution and height. Pre-test and post-test laser scan measurements also indicate roughened surfaces. In contrast, 


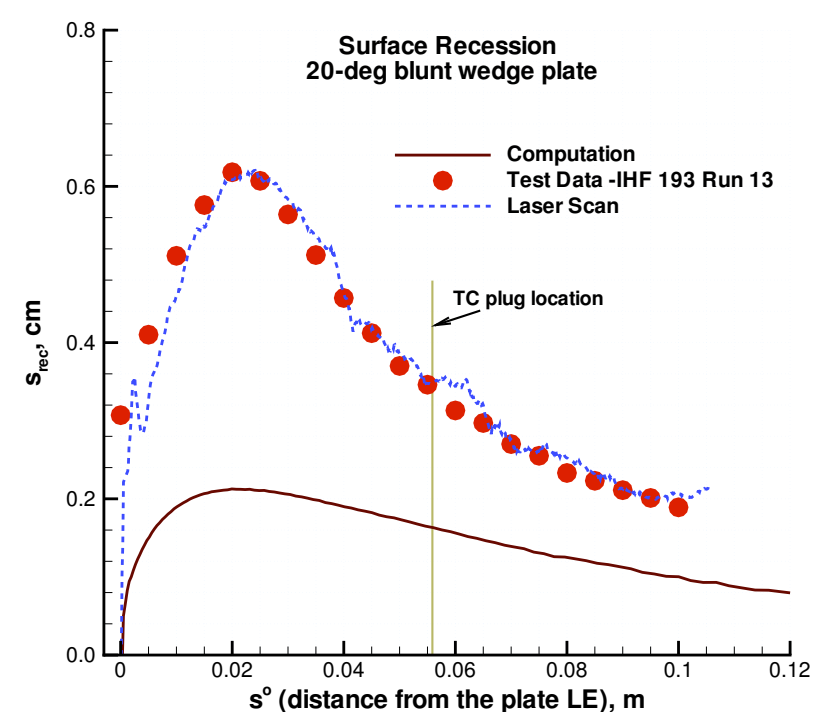

a) Surface recession at $t=20 \mathrm{~s}$

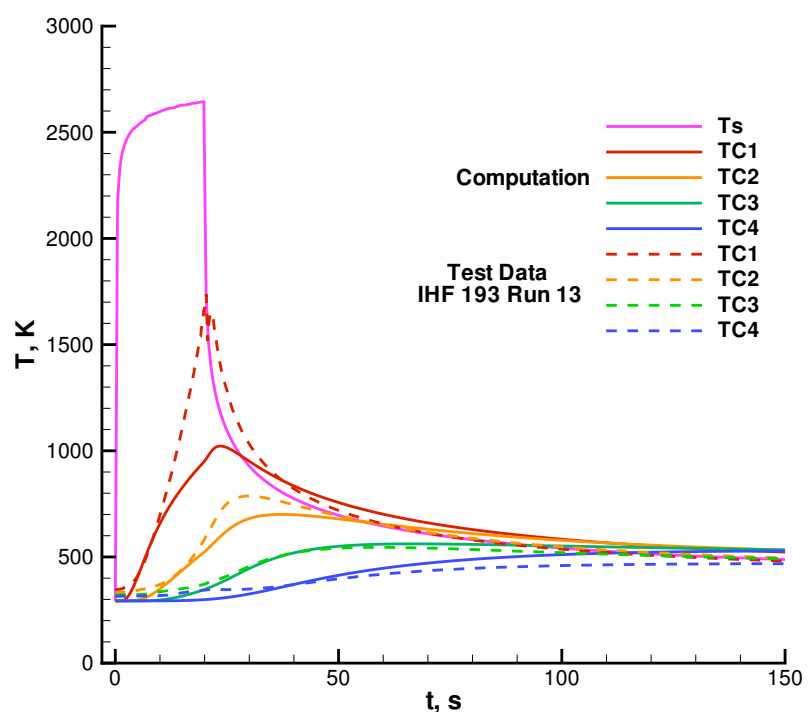

b) In-depth temperatures

Fig. 12 Comparisons of computed recession profiles and thermocouple response with the measurements at Condition 2. IHF 6-inch nozzle flow: $p_{o}=890 \mathrm{kPa}, h_{o}=26.3 \mathrm{MJ} / \mathrm{kg}$, with $6.4 \%$ Ar in air.

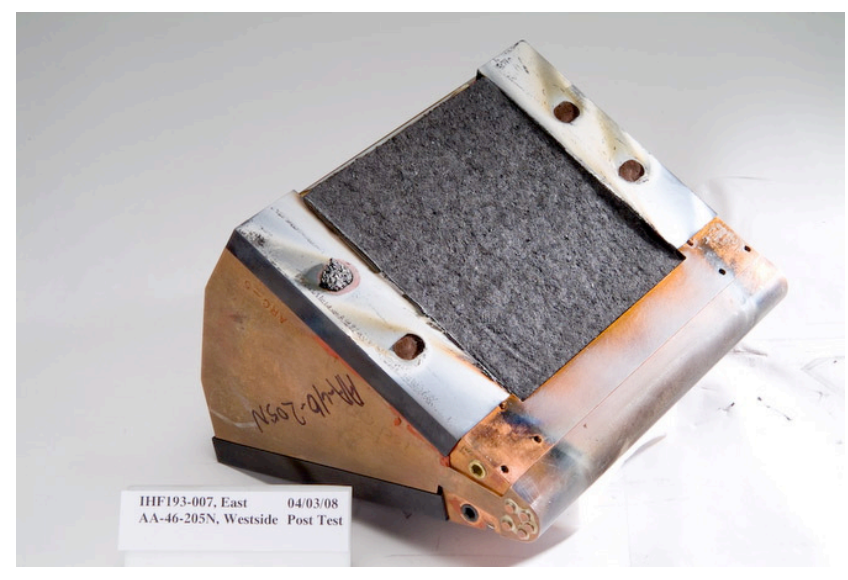

a) Run 7

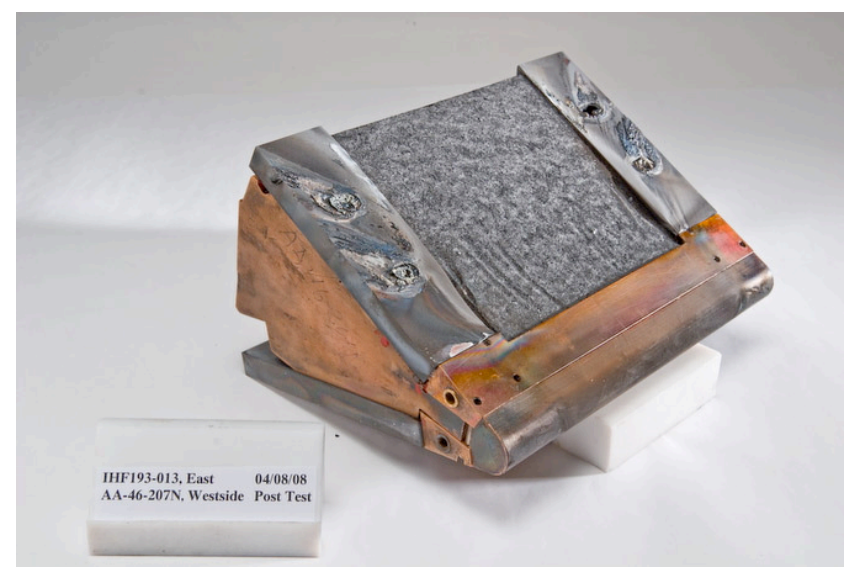

b) Run 13

Fig. 13 Post-test photographs of the PICA samples on the wedge model, IHF 193 tests.

the stagnation models analyzed in Refs. 18-19 showed relatively smooth surfaces after the tests. Also, in Ref. 12, the measured PICA recession and surface temperature data obtained in an AEDC arc-jet facility wedge test were explained by assuming that the flow over the test article was turbulent, while the calibration plate data were explained by laminar flow simulations. Although the AEDC facility is capable of producing turbulent flows (existing calibration plate data at other conditions indicate that the flow is turbulent), there are no existing wedge calibration plate data in the IHF that indicate that the flow is turbulent. The boundary-layer transition over an ablating test article is complex, and it is influenced by several geometry and flow parameters such as Mach number, Reynolds number, surface roughness, surface blowing rates, etc. ${ }^{32}$ The computed momentum thickness Reynolds numbers at the plate leading edge for the two conditions are 69 and 78, respectively, which are consistent with the laminar flow assumption. Even if ablated surface roughness caused the flow over the test article to transition to turbulence at some time during the test, it is almost impossible to determine when the transition occurred. Nevertheless, fully turbulent flow simulations over the wedge model were performed 


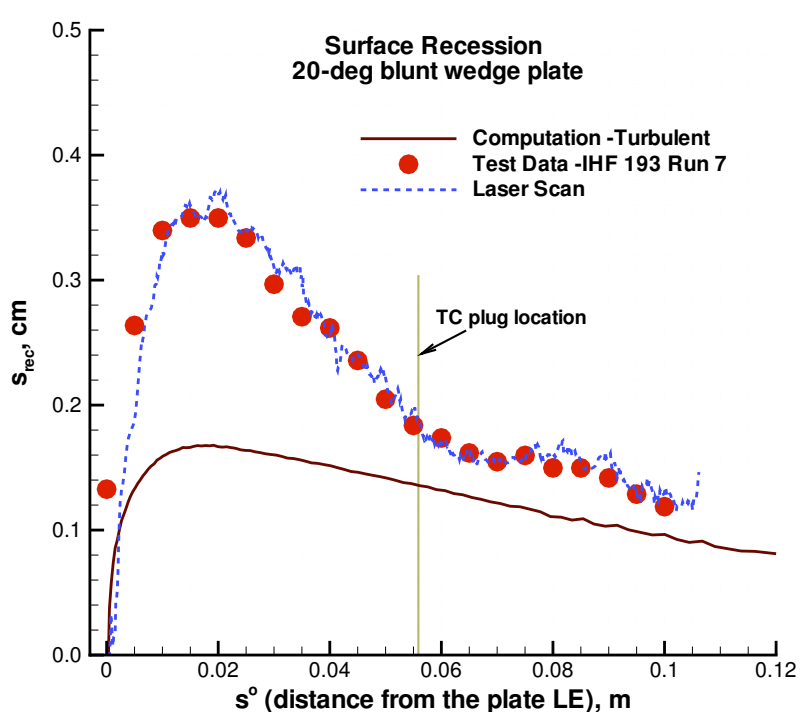

a) Surface recession at $t=20 \mathrm{~s}$

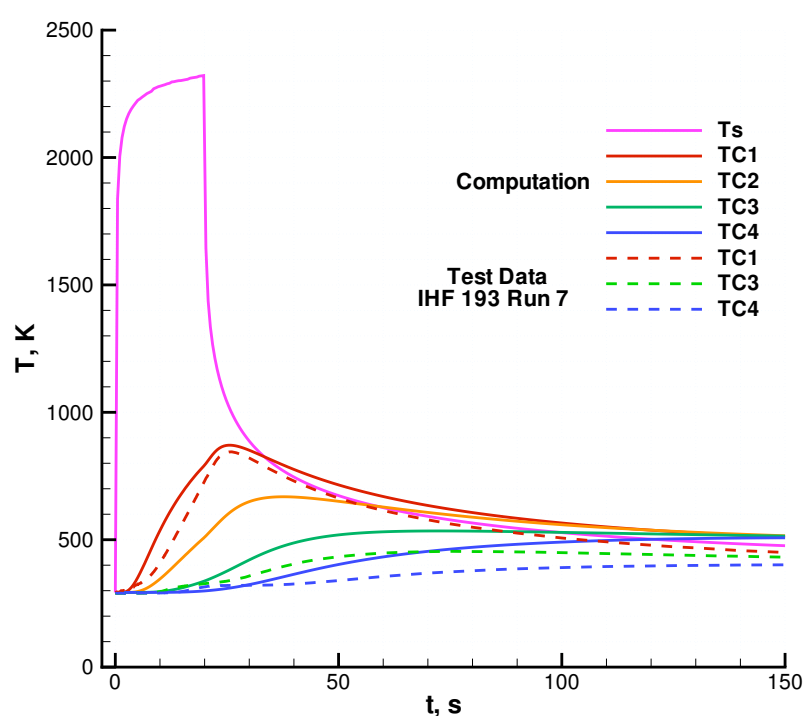

b) In-depth temperatures

Fig. 14 Comparisons of computed turbulent flow recession profiles and thermocouple response with the measurements at Condition 1. IHF 6-inch nozzle flow: $p_{o}=490 \mathrm{kPa}$, $h_{o}=17.9 \mathrm{MJ} / \mathrm{kg}$, with $6.5 \%$ Ar in air.

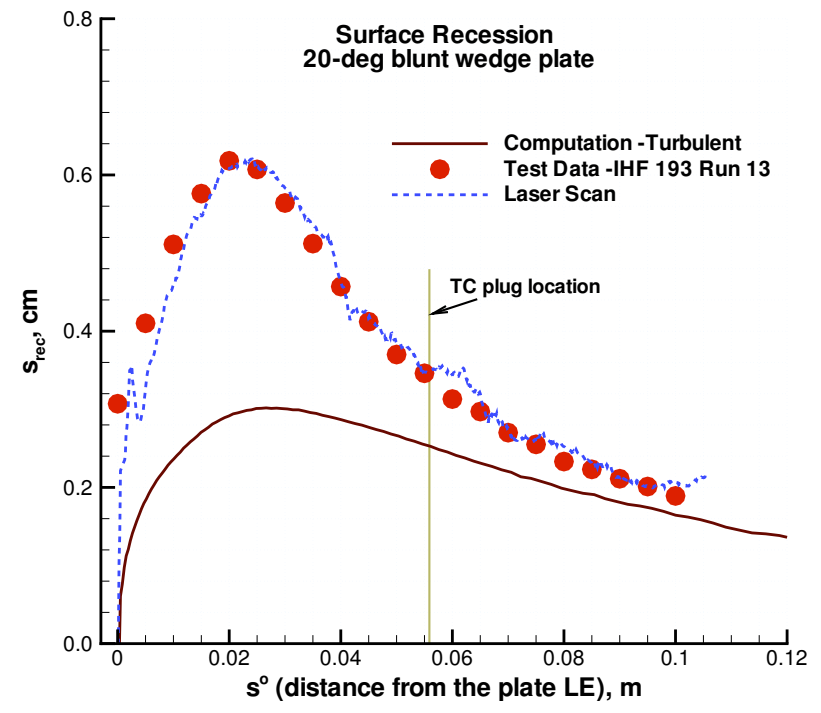

a) Surface recession at $t=20 \mathrm{~s}$

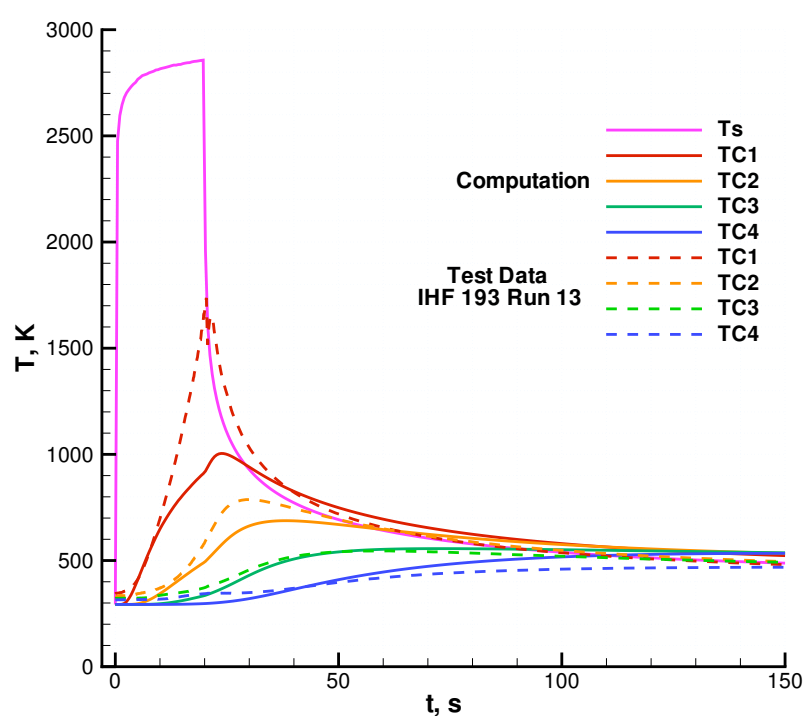

b) In-depth temperatures

Fig. 15 Comparisons of computed turbulent flow recession profiles and thermocouple response with the measurements at Condition 2. IHF 6-inch nozzle flow: $p_{o}=890 \mathrm{kPa}$, $h_{o}=26.3 \mathrm{MJ} / \mathrm{kg}$, with $6.4 \%$ Ar in air.

to establish upper bounds on the surface recession and temperature, at least for the one turbulence model used: the algebraic Baldwin-Lomax turbulence model.

In this section, turbulent flow simulation results and comparisons with the measured recession and in-depth temperatures for the two conditions are presented.

Figure 14 compares the computed recession profiles and in-depth temperatures with IHF 193 Run 7 measurements, assuming turbulent flow over the test plate from the start. The predicted recession is closer to the experiment than it is for the laminar flow. However, the recession near the leading edge of the test plate is still significantly lower than for the experiment. Even the predicted recession at 
$5 \mathrm{~cm}$ downstream of the plate leading edge remains smaller than the measurement by $31 \%$. Temperature comparisons on the other hand have worsened: all TC temperatures are overpredicted, and the computed maximum surface temperature at the TC plug location is $2322 \mathrm{~K}$, higher than both of the pyrometer temperatures. Based on these comparisons, it is unlikely that the discrepancy in surface recession predictions can be explained by transition to turbulent flow over the test plate in this case.

Figure 15 compares the computed recession profiles and in-depth temperatures with IHF 193 Run 13 measurements, assuming turbulent flow over the test plate from the start. Comparisons of both the recession and the temperatures with the measured data have improved somewhat over those with laminar flow. The predicted recession at $5 \mathrm{~cm}$ downstream of the plate leading edge is still smaller than the measurement by $28 \%$. In this case, the near-surface TC temperatures also remain underpredicted, and the computed maximum surface temperature at the TC plug location is $2857 \mathrm{~K}$, lower than both of the pyrometer temperatures. Based on these comparisons, the discrepancy in surface recession predictions could be partially explained if the flow over the test plate were transitioned to turbulent.

\section{E. Uncertainties of Computations and Measurements}

The axisymmetric CFD computations of the nozzle/test-box/model flowfield were performed using multi-block grids with $8.49 \times 10^{4}$ points (the dimensions of the inner computational blocks over the wedge model being $90 \times 120$ and $120 \times 120$ cells). For the material response simulations, a 2-block computational grid was used with grid cell counts of $90 \times 64$ and $120 \times 100$ for the copper and test plate sections, respectively. Based on the authors' judgement, and a limited number of grid refinement studies, the authors believe that the grid quality issues of the computations were adequately addressed. However, CFD computations of arc-jet flows, as for hypersonic flight simulations, include uncertainties in many of the model input parameters. It is not possible at this time to do a complete uncertainty analysis of computed results for all of the simulation input parameters. In the authors' opinion, the most important input parameter is the centerline total enthalpy of the arc-jet test flow. The centerline total enthalpy is not a measured parameter; it is deduced from surface heat flux and pressure measurements on the calibration plate and stagnation-point calorimeter. A complete uncertainty analysis of the calibration plate and stagnation calorimeter measurements is also not available. However, based on empirical evidence (historical Ames arc-jet data), the heat flux measurements are believed to be accurate to within $\pm 15 \%$ and the pressure measurements to within $\pm 5 \%$. Therefore, the CFD estimated enthalpy has an uncertainty of at least $\pm 10-15 \%$, and including other modeling parameters used in CFD, it can be as much as $\pm 20 \%$. Since only fully-catalytic cold-wall heat flux predictions are of interest for the material response analysis, effects of model input parameters, such as chemical reaction rates, surface catalysis, diffusion model, etc., on the computed heat flux values are expected to be secondary.

For the Orion TPS project, the recession measurements obtained both manually and by laser scans generally agree to within $\pm 0.5 \mathrm{~mm}$. The in-depth thermocouples generally provide consistent measurements for several arc-jet runs: the thermocouple devices are estimated to be accurate to within $\pm 1-2 \%$; if the measurement errors related to the thermocouple installations (such as contact resistance) are included, they could be as much as $\pm 5 \%$. The model surface temperatures were measured using one-color and two-color pyrometers. One-color pyrometer measurements in the IHF were found to be more reliable. The measured pyrometer temperatures are believed to be accurate to within $\pm 5 \%$.

\section{F. Discussion}

The analyses of various arc-jet stagnation tests under a wide range of heat flux and pressure conditions showed good agreement (from reasonable to excellent) between the measured and computed PICA recession. ${ }^{14,17,18,19,28}$ However, significant discrepancies between the measured and computed PICA recession in arc-jet wedge tests have been reported in several papers, ${ }^{11,17,33}$ in which one-dimensional and uncoupled material response analyses were used. Various potential reasons for the discrepancy in wedge tests have been offered so far: effects of shear on ablation, effects of the test article shape change, mechanical erosion, increased heating due to roughness of the ablated surface (including transition to turbulence), nonequilibrium surface chemistry (or finite rate surface oxidation), entropy layer over the wedge flowfield, non-similar rates of the heat and oxygen diffusion due to the water-cooled copper wedge 
section, unequal heat and mass transfer coefficients (or a higher mass transfer coefficient than the heat transfer coefficient), etc.

The present analysis suggests that the shape change effects are not entirely responsible for the discrepancy in the PICA recession predictions in wedge tests, at least for IHF 193 tests. The increased heating due to roughness of the ablated surface may be able to explain some of the PICA recession discrepancy in one case, but it is unlikely to explain all of the test data for another case. Also, although they are not conclusive, there are some indications that using different heat and mass transfer coefficients in the material response model might remove some of the discrepancy in recession predictions. The guidance on implementation of unequal heat and mass transfer coefficients in the material response model should come from more accurately coupled simulations. In other words, the accuracy of the present CFD/material-response coupling through a heat-transfer coefficient should be evaluated by means of a higher level fluid-material coupling in which the surface quantities and ablation products/species obtained from the material response simulations are used as surface boundary conditions in the fluid dynamics simulations.

Resolution of these discrepancies in wedge tests is important because they typically increase the margins used in TPS design, as reported in Ref. 11 and 17. It should be noted that during the development of the material response model for PICA, stagnation arc-jet tests were conducted for a wide range of aerothermal heating conditions. In contrast, the available PICA data obtained with wedge tests are limited. For validation of the PICA material response model, it would be useful to expand the wedge database. In particular, it is important to conduct tests at the same condition but at multiple test times so that evolution of the recession profile and in-depth heat transfer can be studied. The multiple test times would also provide insight into validation data if the flow over the test article does indeed transition to turbulence at some point in time due to ablated surface roughness.

\section{Summary and Concluding Remarks}

Coupled fluid-material response analyses of arc-jet wedge tests conducted in the NASA Ames 60MW IHF 6-inch nozzle flow are presented. The ablating material used in these tests was Phenolic Impregnated Carbon Ablator, PICA. The fluid analysis includes a combination of axisymmetric and two-dimensional Navier-Stokes simulations of the nonequilibrium flowfield in the facility nozzle, test box and over the wedge models. The material response analysis includes simulation of two-dimensional surface ablation and internal heat conduction, thermal decomposition, and pyrolysis gas flow. For the ablating test articles, the fluid-material response analyses are loosely coupled in order to take into account changes in surface heating and pressure distributions with shape. The effect of the test article shape change on both fluid and meterial response simulations are demonstrated through comparisons with uncoupled simulations. The effects of the shape change are found to be more pronounced near the plate leading edge mounted on the wedge model.

For two arc-jet conditions, computational predictions are compared with the experimental test data, which included measurements of surface pressure and heat flux on the calibration plate, and measurements of surface recession, surface temperature, and in-depth temperatures for ablating PICA articles. The computations generally predict significantly lower recession and lower surface temperature than the measurements, which is consistent with other published reports in the literature. Comparisons of computed in-depth temperatures with the thermocouple measurements do not provide consistent trends for the two cases. Although several potential factors that may cause the discrepancy in wedge tests are discussed, the source of this discrepancy is not yet understood.

The present fluid-material response analysis coupling primarily addresses the effects of the test article shape change on surface recession predictions by updating the test article surface heat flux and pressure distributions consistent with shape change. However, in order to understand the physics of PICA ablation, such as the injection of ablation products into the model boundary layer and their interactions with the model flowfield, a higher level of fluid-material coupling should be pursued, in which the surface quantities and ablation products/species from the material response simulations are used as surface boundary conditions in the fluid dynamics simulations. 


\section{Acknowledgments}

The authors would like to thank Antonella Alunni for performing laser scans, Jerry Ridge for wedge model preparation and instrumentation, and all of the Thermophysics Facilities Branch Members involved in the Arc-Jet Complex for conducting the tests and providing information on the facilities, in particular, Imelda Terrazas-Salinas, Frank Hui and Enrique Carballo. This work was funded by the NASA Orion TPS Advanced Development and Insight/Oversight Projects. The arc-jet operational capability at Ames is also supported by NASA-SCAP. The support from the NASA Ames Entry Systems and Technology Division through contract NNA04BC25C to ELORET Corporation is gratefully acknowledged.

\section{References}

1 Winovich, W., and Carlson, W., "The 60-MW Shuttle Interaction Heating Facility," 25th ISA Symposium, May 1979.

2 Winovich, W., Balakrishnan, A., and Balboni, J., "Experimental and Analytical Derivation of ArcHeater Scaling Laws for Simulating High-Enthalpy Environments for Aeroassisted Orbital Transfer Vehicle Application," AIAA Paper 85-1006, June 1985.

3 Peterson, A. B., Nichols, F., Mifsud, B., and Love, W., "Arc Jet Testing in NASA Ames Research Center Thermophysics Facilities," AIAA Paper 92-5041, Dec. 1992.

4 Terrazas-Salinas, I., and Cornelison, C., "Test Planning Guide for ASF Facilities," Thermophysics Facilities Branch, Space Technology Division, NASA Ames Research Center, March 1999.

5 "Thermophysics Facilities Branch Fact Sheet," Thermophysics Facilities Branch, Space Technology Division, NASA Ames Research Center, Jan. 2005.

6 Stewart, D. A., Squire, T., Gökçen, T., and Henline, W., "Arc-Jet Flight Simulation Tests for X-37 Wing Leading Edge TPS," X-37 Report for ARC 05 Task 02, Oct. 2004.

7 Gökçen, T., and Stewart, D. A., "Computational Analysis of Semi-elliptical Nozzle Arc-jet Experiments: Calibration Plate, Wing Leading Edge," AIAA Journal, Vol. 45, No. 1, Jan. 2007, pp. 128-137; also AIAA Paper 2005-4887, June 2005.

8 Gökçen, T., Raiche, G. A., Driver, D. M., Balboni, J. A., and McDaniel, R. D., "Applications of CFD Analysis in Arc-Jet Testing of RCC Plug Repairs," AIAA Paper 2006-3291, June 2006.

9 Gökçen, T., Skokova, K., Balboni, J. A., Terrazas-Salinas, I., and Bose, D., "Computational Analysis of Arc-Jet Wedge Calibration Tests in IHF 6-Inch Conical Nozzle," AIAA Paper 2009-1348, Jan. 2009.

10 Prabhu, D., Saunders, D., Tang, C., Terrazas-Salinas, I., Carballo, E., and Driver, D., "CFD Analysis Framework for Arc-Heated Flowfields, II: Shear Testing in Arc-jets at NASA ARC," AIAA Paper 2009-4081, June 2009.

11 Driver, D. M., Carballo, J. E., Beck, R., Prabhu, D., Santos, J. A., Cassell, A., Skokova, K., Tang, C., Hwang, H. H., Slimko, E., Willcockson, W., and Songer, J., "Arc Jet Testing in a Shear Environment for Mars Science Laboratory Thermal Protection System," AIAA Paper 2009-4230, June 2009.

12 White, T. R., Sepka, S. A., Beck, R. A., and Smith, D. M., "CFD and Material Response Framework for Wedge Testing in AEDC H2," AIAA Paper 2009-4233, June 2009.

13 Chen, Y.-K., Milos, F. S., and Gökçen, T., "Loosely Coupled Simulation for Two-Dimensional Ablation and Shape Change," AIAA Paper 2008-3802, June 2008.

14 Gökçen, T., Chen, Y.-K., Skokova, K., and Milos, F. S., "Computational Analysis of Arc-Jet Stagnation Tests Including Ablation and Shape Change," AIAA Paper 2009-3596, June 2009. 
15 Tran, H., Johnson, C. E., Rasky, D. J., Hui, F. C., Hsu, M.-T., Chen, T., Chen, Y.-K., Paragas, D., and Kobayashi, L., "Phenolic Impregnated Carbon Ablators (PICA) as Thermal Protection Systems for Discovery Missions," NASA TM-110440, April 1997.

16 Covington, M. A., Heinemann, J. M., Goldstein, H. E., Chen, Y.-K., Terrazas-Salinas, I., Balboni, J. A., Olejniczak, J., and Martinez, E. R., "Performance of a Low Density Ablative Heat Shield Material," Journal of Spacecraft and Rockets, Vol. 45, No. 2, March-April 2008, pp. 237-247; also AIAA Paper 2004-2273, June 2004.

17 Bose, D., Skokova, K, Wright, M. J., and Reuther, J., "Ground-to-Flight Traceability Analysis of Arcjet Testing for the Crew Exploration Vehicle," AIAA Paper 2009-3845, June 2009.

18 Milos, F. S., and Chen, Y.-K., "Two-Dimensional Ablation, Thermal Response and Sizing Program for Pyrolyzing Ablators," Journal of Spacecraft and Rockets, Vol. 46, No. 6, November-December 2009, pp. 1089-1099; also AIAA Paper 2008-1223, Jan. 2008.

19 Milos, F. S, and Chen, Y.-K., "Ablation and Thermal Response Property Model Validation for Phenolic Impregnated Carbon Ablator," AIAA Paper 2009-262, Jan. 2009.

20 Smith, M. D., Moody, H., Wanstall, C., and Terrazas-Salinas, I., "The Design and Use of Calorimeters for Characterization of High-Enthalpy Flows in Arc-Heated Test Facilities," AIAA Paper 20025236, Sept. 2002.

21 Wright, M. J., Candler, G. V., and Bose, D., "Data-Parallel Line Relaxation Method for the NavierStokes Equations," AIAA Journal, Vol. 36, No. 9, Sept. 1998, pp. 1603-1609.

${ }^{22}$ Wright, M. J., "Data-Parallel Line Relaxation (DPLR) Code, Version 3.05," Private Communication, June 2006.

23 Park, C., Nonequilibrium Hypersonic Aerothermodynamics, John Wiley \& Sons, Inc., New York, 1990, Chap. 4.

24 Park, C., "Assessment of a Two-Temperature Kinetic Model for Dissociating and Weakly Ionizing Nitrogen," Journal of Thermophysics and Heat Transfer, Vol. 2, No. 1, 1988, pp. 8-16.

25 Baldwin, B. and Lomax, H., "Thin Layer Approximation and Algebraic Model for Separated Turbulent Flows," AIAA Paper 78-257, Jan. 1978.

26 Chen, Y.-K., and Milos, F. S., "Two-Dimensional Implicit Thermal Response and Ablation Program for Charring Materials," Journal of Spacecraft and Rockets, Vol. 38, No. 4, July-August 2001, pp. 473-481.

27 Chen, Y.-K., Milos, F. S., Reda, D. C., and Stewart, D. A., "Graphite Ablation and Thermal Response Simulation Under Arc-Jet Flow Conditions," AIAA Paper 2003-4042, June 2003.

28 Chen, Y.-K., Gökçen, T., and Edquist, K. T., "Two-Dimensional Ablation and Thermal Response Analyses for Mars Science Laboratory Heatshield," AIAA Paper 2009-4235, June 2009.

29 Milos, F. S, and Chen, Y.-K., "Ablation and Thermal Property Model for Phenolic Impregnated Carbon Ablator (PICA)," NASA/TM-2009-215377, March 2009.

30 Squire, T., Milos, F. S., and Hartlieb, G. C., "Aerospace Materials Property Database (TPSX)," Journal of Spacecraft and Rockets, Vol. 46, No. 3, May-June 2009, pp. 733-736.

31 "Gridgen, Version 15.11," Pointwise, Inc., Fort Worth, TX.

32 Schneider, S. P., "Hypersonic Boundary-Layer Transition with Ablation and Blowing," Journal of Spacecraft and Rockets, Vol. 47, No. 2, March-April 2010, pp. 225-237.

33 Driver, D. M., Olson, M. W., Barnhardt, M. D., and MacLean, M., "Understanding High Recession Rates of Carbon Ablators Seen in Shear Tests in an Arc Jet," AIAA Paper 2010-1177, Jan 2010. 